\title{
Methods for assessing the effects of spatial luminance patterns on perceived qualities of concert lighting
}

\section{VWL Lo PhD and KA Steemers PhD}

Department of Architecture, The Martin Centre for Architectural and Urban Studies, University of Cambridge, Cambridge, UK

Short title: Assessing effects of spatial luminance patterns

Received 14 October 2018; Revised 24 February 2019; Accepted 25 February 2019

This paper presents experimental approaches for evaluating concert lighting from the viewpoints of audience members and performers in Cambridge King's College Chapel. We develop image zoning and abstraction techniques to quantify and interpret photometric data acquired under four different electric lighting conditions. Assessed by 78 participants, these lighting scenarios are compared across six different viewing positions using a set of structured questionnaires. Ordered logistic regression modelling shows that the ratios and functions describing uniformity, brightness and light patterns are common explanatory variables for predicting perceived visual clarity, visual uniformity, brightness and spatial intimacy. Uniformity-related attributes are observed to be among the strongest variables for all these perceived qualities, except for visual clarity, which is better explained by acuity-related measures. These experimental results confirm the applicability of our approaches, highlighting the importance of combining multiple methods and integrating complex architectural situations into the process of understanding luminous appearance.

Address for correspondence: Villian Lo, Department of Architecture, The Martin Centre for Architectural and Urban Studies, University of Cambridge, 1-5 Scroope Terrace, Cambridge CB2 1PX, UK.

E-mail: villianlo@cantab.net 


\section{Introduction}

Understanding the perceived qualities of a visual environment in relation to its occupants requires more than understanding the visual scenes in part because our visual system engages in higher-order perceptual activities. Much of the interest in this field of lighting research is driven by the pressing need to reduce lighting energy consumption, ${ }^{1-3}$ the desire to improve occupants' well-being, ${ }^{4-6}$ and the incentive provided by new technologies. ${ }^{7-10}$ Progress however has been slow due not only to the difficulties in gauging higher-order perceptions (i.e. perceptual patterns), but also to the challenges into acquiring comprehensive and yet meaningful data describing luminous environments (i.e. visual stimuli and sensations). In search of empirical relations between perceived qualities and objective measures, the lighting community often perform laboratory studies ${ }^{11-13}$ in an attempt to focus on specific lighting aspects.

Early research on lighting quality relied on photometers, ${ }^{14-16}$ the Weber-Fechner $\operatorname{law}^{17-20}$ and the cosine law of incidence ${ }^{21,22}$ to describe light in numerical terms. Indices and ratios were then derived for evaluating lighting effects on behavioural responses. The use of psychophysical methods including questionnaires, semantic differential scaling and paired comparisons have also become an essential tool for measuring subjective responses. The increasing complexity of research questions has also led to the use of applied statistics. With the invention of the charge-couple device and the video camera, more effort has been devoted to studying the effects of lit appearance on lighting perception. ${ }^{13,23}$ The seminal work of Flynn et al. ${ }^{24,25}$, Hawkes et al. ${ }^{26}$ and Loe et al. ${ }^{11,27}$ have provided the lighting community with broad conceptual approaches to evaluating impressions. Their findings however were of suggestive nature, focusing 
merely on generic office and conference environments with little attention paid to architectural implications brought about by real settings.

Drawing upon behavioural conception, sociological and psychological theories, ${ }^{28,29}$ Flynn et $a l .{ }^{24}$ combined associational and scaling techniques — factor analysis, stepwise multiple regression and multi-dimensional scaling — into a comprehensive analytical procedure. Their experiments were performed in a conference room under 6 different lighting conditions. 12 groups of 8 subjects participated in the study. They were instructed to make comparative judgements of the conditions and to indicate their responses using 34 semantic differential scales, for example, like/dislike, bright/dim, and spacious/cramped. Flynn was able to group the scales into three perceptual factors - evaluative impression, perceptual clarity and impression of spaciousness - providing some evidence in support of their view that similar light characteristics can impart shared impressions of a luminous environment.

In the same study, moreover, a separate paired comparative test was performed to test the relative similarity or difference among the conditions. 46 subjects were instructed to record their responses on a numerical scale of one to ten. They found that the reported impressions, perceptions of clarity and spaciousness were best explained by a combination of three factors: ‘bright/dim', ‘uniform/non-uniform' and 'peripheral lighting/overhead lighting'. The reported strength of correlation for evaluative impressions ( $r=0.94)$, perceptual clarity $(r=0.99)$ and spaciousness $(r=0.98)$ however seems suspicious. Surely there are other unmeasurable factors influencing our perceptions, so such near-perfect correlation seems unlikely to describe the perceptual relationships fully. In follow-up studies on low energy and non-uniform lighting, Flynn 
appeared to show that cue patterns can induce impressions of clarity, spaciousness, relaxation and pleasantness. ${ }^{25}$

Within this line of research, Hawkes et $a l .{ }^{26}$ have also attempted to deepen the understanding through an experiment in a windowless office with 18 different light settings. 28 subjects were instructed to indicate their responses using 15 semantic differential scales related to visual interest. They attempted to associate the responses with physical measures such as horizontal and vertical illuminances, scalar and vector illuminances, and cylindrical illuminance. They however did not observe any definite correlation patterns.

For the same experimental settings but unlike previous attempts, Loe et al. assessed the responses against detailed luminance maps, specifically within a $40^{\circ}$ horizontal band centred at the eye. ${ }^{27}$ Regression analyses indicated that there were high correlations between the visual lightness, visual interest and luminance distributions. In particular, the perceptual factors appeared to correlate strongly with average luminance and the maximum to minimum luminance ratio within the $40^{\circ}$ band. Contrary to these findings, their subsequent studies failed to achieve similar correlations. ${ }^{11}$ They observed that the standard deviation and interquartile range of luminance give better correlation instead.

Despite rigorous efforts to formulate protocols for evaluating lit appearances, this review identifies several methodological issues:

- There seems little doubt that different environments would require different sets of variables and scales to describe the corresponding lit appearances depending on context, function and occupant requirements. While Flynn made reference to Osgood's semantic differential scales and Hawkes et al. referred to Flynn and 
Küller's studies, Loe et al. did not specify exactly how their selection was made but merely noted it was based upon previous studies. It is worth noting that the nature of the context studied is somewhat different: some focused on offices and others on conference rooms. The lack of justification in variable selection raised the question of how to compare observations and findings for further development, as well as to apply them in other settings.

- The use of a single viewing position (except in Flynn's and Hawkes' follow-up studies) for assessments could have led to missing critical visual information. It is plausible that using an inadequate description of the luminous environment in their regression analysis resulted in the discrepancy in correlations.

- Loe’s approach using luminance-based variables can be seen as a critical step forward in order to highlight the importance of evaluating responses against data that represents more accurately the way we see light (i.e. illuminance $\mathrm{x}$ reflectance). There are convergence-divergence eye movements or saccades during visual search and field scanning before the eye performs micro-scans of the stimuli for clear foveal vision. ${ }^{30}$ Focusing on the $40^{\circ}$ band may thus seem to have overlooked the fact that occupants see things by relating themselves to their visual environment rather than limiting their view to a certain region.

Flynn, Hawkes and Loe’s efforts paved the way for today's lit appearance studies. Ordinary linear and multiple regression modellings are commonly applied to study the relationships among different aspects of visual environment and their effects on perceptions, preferences, satisfaction, comfort and health (Table 1). Many of these studies collected subjective data using discrete rating scales. It could be argued that fitting such data into ordinary multiple regression models might give a somewhat 
misleading view of the relationships among the variables, in part because the values of the predictors and the outcome variables are assumed to be continuous and noninteger. ${ }^{31,32}$ Responses collected using Likert scales clearly violate this assumption. 
Table 1. Modelling methods adopted by lighting researchers

\begin{tabular}{|c|c|c|c|}
\hline Study & Focus of study & Assessment & Modelling technique(s) \\
\hline Flynn et al. ${ }^{24}$ & $\begin{array}{l}\text { Lighting effects on } \\
\text { impression and } \\
\text { behaviour }\end{array}$ & $\begin{array}{l}\text { - Semantic differential scales / } \\
\text { Line scales }\end{array}$ & $\begin{array}{l}\text { - Factor analysis } \\
\text { - Stepwise multiple } \\
\text { regression } \\
\text { - Multi-dimensional } \\
\text { analysis }\end{array}$ \\
\hline Stone et $a .^{33}$ & $\begin{array}{l}\text { Subjective qualities } \\
\text { of light in seven } \\
\text { lecture rooms }\end{array}$ & $\begin{array}{l}\text { - Similarity judgements } \\
\text { - Fifteen-point scales } \\
\text { - Multi-dimensional scales }\end{array}$ & $\begin{array}{l}\text { - Stepwise linear } \\
\text { regression } \\
\text { - Multi-dimensional } \\
\text { analysis }\end{array}$ \\
\hline $\begin{array}{l}\text { Hawkes et } \\
\text { al. }{ }^{26}\end{array}$ & $\begin{array}{l}\text { Preferred office } \\
\text { lighting quality, } \\
\text { complexity and } \\
\text { brightness }\end{array}$ & $\begin{array}{l}\text { - Multi-dimensional scales } \\
\text { - Iso-preference lines }\end{array}$ & $\begin{array}{l}\text { - Multi-dimensional } \\
\text { analysis } \\
\text { - Factor analysis }\end{array}$ \\
\hline Flynn ${ }^{25}$ & $\begin{array}{l}\text { Non-uniform lighting } \\
\text { effects on evaluative } \\
\text { impressions, clarity, } \\
\text { spaciousness, } \\
\text { relaxation and } \\
\text { pleasantness }\end{array}$ & $\begin{array}{l}\text { - Semantic differential scales / } \\
\text { Line scales } \\
\text { - Multi-dimensional scales }\end{array}$ & $\begin{array}{l}\text { - Multiple linear } \\
\text { regression } \\
\text { - Analysis of variance }\end{array}$ \\
\hline Loe et $a .^{27}$ & $\begin{array}{l}\text { Effects of luminous } \\
\text { environment and } \\
\text { distribution on visual } \\
\text { interest and lightness }\end{array}$ & $\begin{array}{l}\text { - Semantic differential scales / } \\
\text { Line scales }\end{array}$ & $\begin{array}{l}\text { - Factor analysis } \\
\text { - Logarithmic correlation } \\
\text { analysis }\end{array}$ \\
\hline Pellegrino $^{34}$ & $\begin{array}{l}\text { Visual performance } \\
\text { and overall } \\
\text { environmental } \\
\text { appearance in an } \\
\text { office }\end{array}$ & $\begin{array}{l}\text { - Seven-point semantic } \\
\text { differential scales } \\
\text { - Seven-point questionnaire }\end{array}$ & $\begin{array}{l}\text { - Multiple regression } \\
\text { analysis }\end{array}$ \\
\hline $\begin{array}{l}\text { Newsham and } \\
\text { Veitch }^{35}\end{array}$ & $\begin{array}{l}\text { Relationship between } \\
\text { task performance, } \\
\text { individual's lighting } \\
\text { control and } \\
\text { preferences }\end{array}$ & $\begin{array}{l}\text { - Categorical independent } \\
\text { variables }\end{array}$ & $\begin{array}{l}\text { - Linear regression } \\
\text { - Third-order polynomial } \\
\text { regression } \\
\text { - Post-hoc data analysis } \\
\text { - Categorical analysis }\end{array}$ \\
\hline Houser et al. ${ }^{36}$ & $\begin{array}{l}\text { Changes in responses } \\
\text { to direct and indirect } \\
\text { lighting systems }\end{array}$ & $\begin{array}{l}\text { - Paired comparison } \\
\text { - Semantic differential scaling }\end{array}$ & $\begin{array}{l}\text { - Tukey method / } \\
\text { multiple comparison } \\
\text { grouping }\end{array}$ \\
\hline Custers et al. ${ }^{37}$ & $\begin{array}{l}\text { Relationship between } \\
\text { perceived retail } \\
\text { environments and } \\
\text { physical attributes of } \\
\text { light }\end{array}$ & $\begin{array}{l}\text { - Card-sorting (into five } \\
\text { categories) for evaluating } \\
\text { interiors impression } \\
\text { - Seven-point Likert scales for } \\
\text { assessing atmosphere perception }\end{array}$ & $\begin{array}{l}\text { - Multiple } \\
\text { correspondence analysis } \\
\text { - Multiple regression } \\
\text { analysis }\end{array}$ \\
\hline $\begin{array}{l}\text { Schielke and } \\
\text { Leudesdorff }^{38}\end{array}$ & $\begin{array}{l}\text { Effects of retail } \\
\text { lighting on brand }\end{array}$ & - Seven-point Likert scales & - Linear regression \\
\hline
\end{tabular}


Imaging techniques are well accepted because of their effectiveness and accuracy in collecting unprecedentedly detailed luminous and spatial data. ${ }^{2,39-42}$ The emergence of high dynamic range (HDR) imaging has given rise to more advanced and accurate luminance mapping techniques and has given a fresh impetus to lighting research. Essentially, an HDR image which consists of multiple low dynamic range images captured at a fixed aperture setting but with various shutter speeds is capable of acquiring (almost) real-world luminances. Table 2 summaries the use of HDR imaging techniques in this field of research.

HDR imaging is not new especially to the fields of photography $y^{8,43,44}$ and lighting simulation ${ }^{45,46}$. The accuracy of using HDR imaging to measure luminance has been validated for quite some time..$^{39,47,48}$ Apart from using it for luminance mapping and identifying glare sources, the potential of photometric data captured remains largely underexplored. Its application in lighting research is still far from being a routine practice owing to a lack of standard, a lack of clarity about how best to dissect an HDR image into meaningful regions for extracting information selectively, and less often is it studied in real complex settings. 
Table 2. Applications of HDR imaging in spatial luminance studies

\begin{tabular}{|c|c|c|c|c|}
\hline Study & Focus of study & Analytical technique(s) & Setting(s) & Occupied? \\
\hline $\begin{array}{l}\text { Fan et al. }{ }^{41} \\
\text { Painter et al. }{ }^{49}\end{array}$ & $\begin{array}{l}\text { - Developed a long-term } \\
\text { approach to collecting } \\
\text { data for visual comfort } \\
\text { analysis } \\
\text { - Examined glare } \\
\text { perception, visual and } \\
\text { thermal comfort }\end{array}$ & - Luminance mapping & $\begin{array}{l}\text { Single } \\
\text { occupancy } \\
\text { office }\end{array}$ & Yes \\
\hline Tural $^{42}$ & $\begin{array}{l}\text { - Integrated HDR } \\
\text { imaging into post- } \\
\text { occupancy evaluation }\end{array}$ & $\begin{array}{l}\text { - Luminance mapping } \\
\text { - Iso-plots } \\
\text { - False-colour } \\
\text { illuminance mapping } \\
\text { - False-colour luminance } \\
\text { task to background } \\
\text { contrast ratio plots }\end{array}$ & Offices & No \\
\hline Bellia et al. ${ }^{2}$ & $\begin{array}{l}\text { - Examined task } \\
\text { performance, glare and } \\
\text { visual comfort }\end{array}$ & - Luminance mapping & School & No \\
\hline Konis et al. ${ }^{50}$ & $\begin{array}{l}\text { - Studied the association } \\
\text { of visual comfort with } \\
\text { shading systems }\end{array}$ & $\begin{array}{l}\text { - Luminance mapping } \\
\text { - False-colour tone- } \\
\text { mapping } \\
\text { - Bitmap masking } \\
\text { (windows, computer } \\
\text { screen and desktop) }\end{array}$ & Office & No \\
\hline $\mathrm{Cai}^{51}$ & $\begin{array}{l}\text { - Introduced luminance } \\
\text { gradient metric for } \\
\text { lighting evaluation } \\
\text { - Examined spatial and } \\
\text { temporal luminance } \\
\text { changes }\end{array}$ & $\begin{array}{l}\text { - Luminance mapping } \\
\text { - Gradient magnitude } \\
\text { mapping } \\
\text { - Two-dimensional and } \\
\text { three-dimensional } \\
\text { gradient mappings }\end{array}$ & Laboratory & No \\
\hline $\begin{array}{l}\text { van den } \\
\text { Wymelenberg } \\
\text { and Inanici }\end{array}$ & $\begin{array}{l}\text { - Examined illuminance- } \\
\text { based metrics for } \\
\text { predicting visual comfort }\end{array}$ & $\begin{array}{l}\text { - Luminance mapping } \\
\text { - False-colour tone- } \\
\text { mapping } \\
\text { - Regional masking (task } \\
\text { zones, glare sources, } \\
\text { windows) }\end{array}$ & $\begin{array}{l}\text { Laboratory/ } \\
\text { Office }\end{array}$ & No \\
\hline Zhao et al. ${ }^{53}$ & $\begin{array}{l}\text { - Developed methods to } \\
\text { facilitate perceptual- } \\
\text { control analysis }\end{array}$ & - Image-based mapping & $\begin{array}{l}\text { Offices } \\
\text { - Laboratory } \\
\text { / Renderings }\end{array}$ & No \\
\hline
\end{tabular}


An appraisal of concert lighting for the King's College Chapel in Cambridge was prompted by complaints about its low illuminance, uneven luminous distribution and the visual distraction said to be caused by the present rig lighting installation. Having recognised the importance of performing lighting experiments in real, complex and occupied settings, ${ }^{54}$ we took the opportunity to use the chapel as a test bed for our methodological developments: i) examine the applicability of methods in a real setting with architectural significance; ii) investigate techniques to extract meaningful patterns and data from HDR images, and iii) identify possible subjective-objective connections.

\section{Methods and procedures}

\subsection{Field experiments}

The experiments were conducted in a performance area of $139 \mathrm{~m}^{2}$ under four electric light settings (Figure 1). Similar to our previous field investigations on occupied spaces, peripheral wall lighting (crown uplight ${ }^{(\mathrm{a})}$ and wooden screen spotlights ${ }^{(\mathrm{b})}$ (Table 3)) remained on during all the experimental sessions. A detailed description of the experimental space and layout has been given in Lo and Steemers. ${ }^{54}$

78 participants were recruited from across the University of Cambridge to take part in these evening experiments. Prior to the experiment, the participants were briefed about its aim and the procedure. They were asked to imagine themselves attending a performance in the chapel [or performing in an orchestra or chorus appearing there]. 
Figure 1. Four electric light settings*

I: Interim Lighting

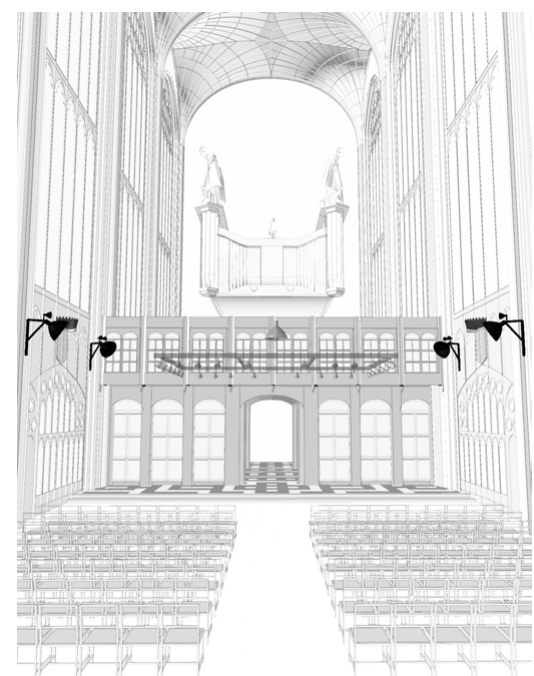

Peripheral lights:

- 4 sets of light fixtures were mounted on the North and South walls. Each set consisted of a Megaman 320 w energysaving fluorescent lamp ${ }^{(\mathrm{c})}$ and 2 supplementary 16 w Philips MasterLed spotlights $^{(\mathrm{d})}$.

III: All Lighting

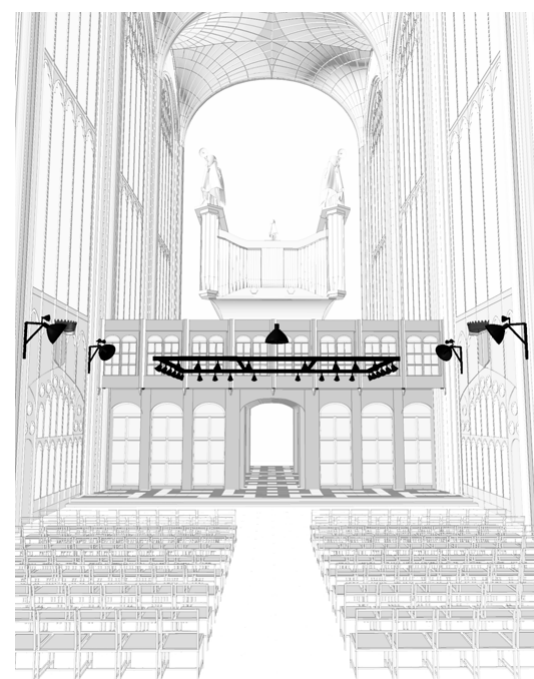

Peripheral lights, overhead rig lights and overhead spotlight:

- Setting I + Setting IV

* See Table 3 for detailed specifications
II: Interim Plus

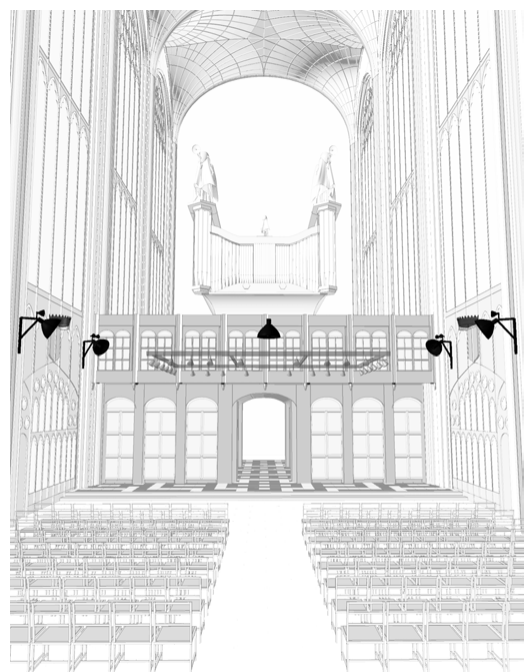

Peripheral lights and overhead spotlight:

- Setting I + A Megaman 320 w energysaving fluorescent lamp suspended ${ }^{(\mathrm{c})}$ at $4 \mathrm{~m}$ high

IV: Rig Lighting (control setting)

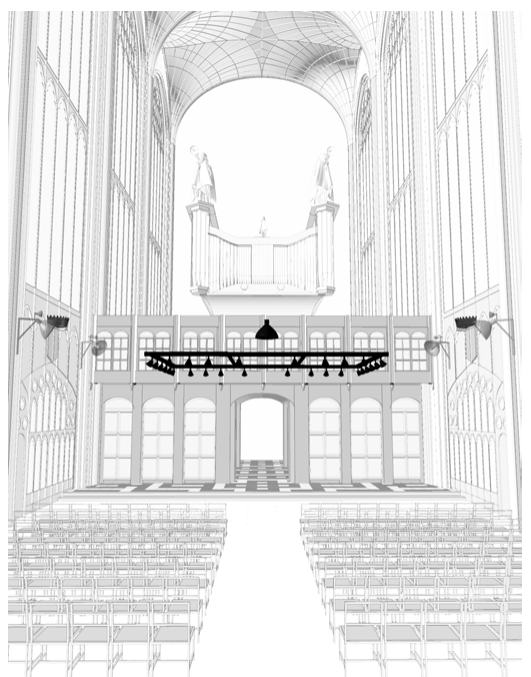

Overhead rig lights and overhead spotlight:

- 28 Havells Sylvania Hi-Spot 95 halogen lights $^{(\mathrm{e})}$

- A Megaman 320 w energy-saving fluorescent lamp ${ }^{(\mathrm{c})}$ suspended at $4 \mathrm{~m}$ high 
Table 3. Specification details of the light fittings

\begin{tabular}{|c|c|c|c|c|c|c|}
\hline \multicolumn{2}{|c|}{ Type of light fitting } & \multirow{2}{*}{$\begin{array}{l}\text { Watts } \\
10 \mathrm{w}\end{array}$} & \multirow{2}{*}{$\begin{array}{c}\begin{array}{c}\text { Luminous } \\
\text { flux }\end{array} \\
370 \mathrm{~lm}\end{array}$} & \multirow{2}{*}{$\begin{array}{c}\begin{array}{c}\text { Luminous } \\
\text { intensity }\end{array} \\
900 \mathrm{~cd}\end{array}$} & \multirow{2}{*}{$\begin{array}{c}\begin{array}{c}\text { Cut-off } \\
\text { angle }\end{array} \\
180^{\circ}\end{array}$} & \multirow{2}{*}{$\begin{array}{c}\begin{array}{c}\text { Beam } \\
\text { angle }\end{array} \\
36^{\circ}\end{array}$} \\
\hline a. $\mathrm{GE}$ & $\begin{array}{l}\text { GE Par30 } \\
\text { Multi-LED }\end{array}$ & & & & & \\
\hline Megaman & $\begin{array}{l}\text { Dimmable PAR38 } \\
\text { energy-saving } \\
\text { fluorescent floodlight }\end{array}$ & $100 \mathrm{w}$ & $597 \mathrm{~lm}$ & $295 \mathrm{~cd}$ & $180^{\circ}$ & $110^{\circ}$ \\
\hline Megaman & $\begin{array}{l}\text { Clusterlite energy- } \\
\text { saving fluorescent } \\
\text { lamp with aluminium } \\
\text { reflector }\end{array}$ & $320 \mathrm{w}$ & $23000 \mathrm{~lm}$ & $3528 \mathrm{~cd}$ & $66^{\circ}$ & $112^{\circ}$ \\
\hline d. $\quad$ Philips & $\begin{array}{l}\text { MasterLed Spot } \\
\text { PAR38 MV }\end{array}$ & $16 \mathrm{w}$ & $600 \mathrm{~lm}$ & $2800 \mathrm{~cd}$ & $180^{\circ}$ & $25^{\circ}$ \\
\hline $\begin{array}{ll}\text { e. } & \text { Havells } \\
& \text { Sylvania }\end{array}$ & Halogen Hi-Spot 95 & $75 \mathrm{w}$ & $640 \mathrm{~lm}$ & $1686 \mathrm{~cd}$ & $81^{\circ}$ & $30^{\circ}$ \\
\hline
\end{tabular}


Figure 2. Fish-eye images of the twenty-four visual scenarios (available in colour in online version)

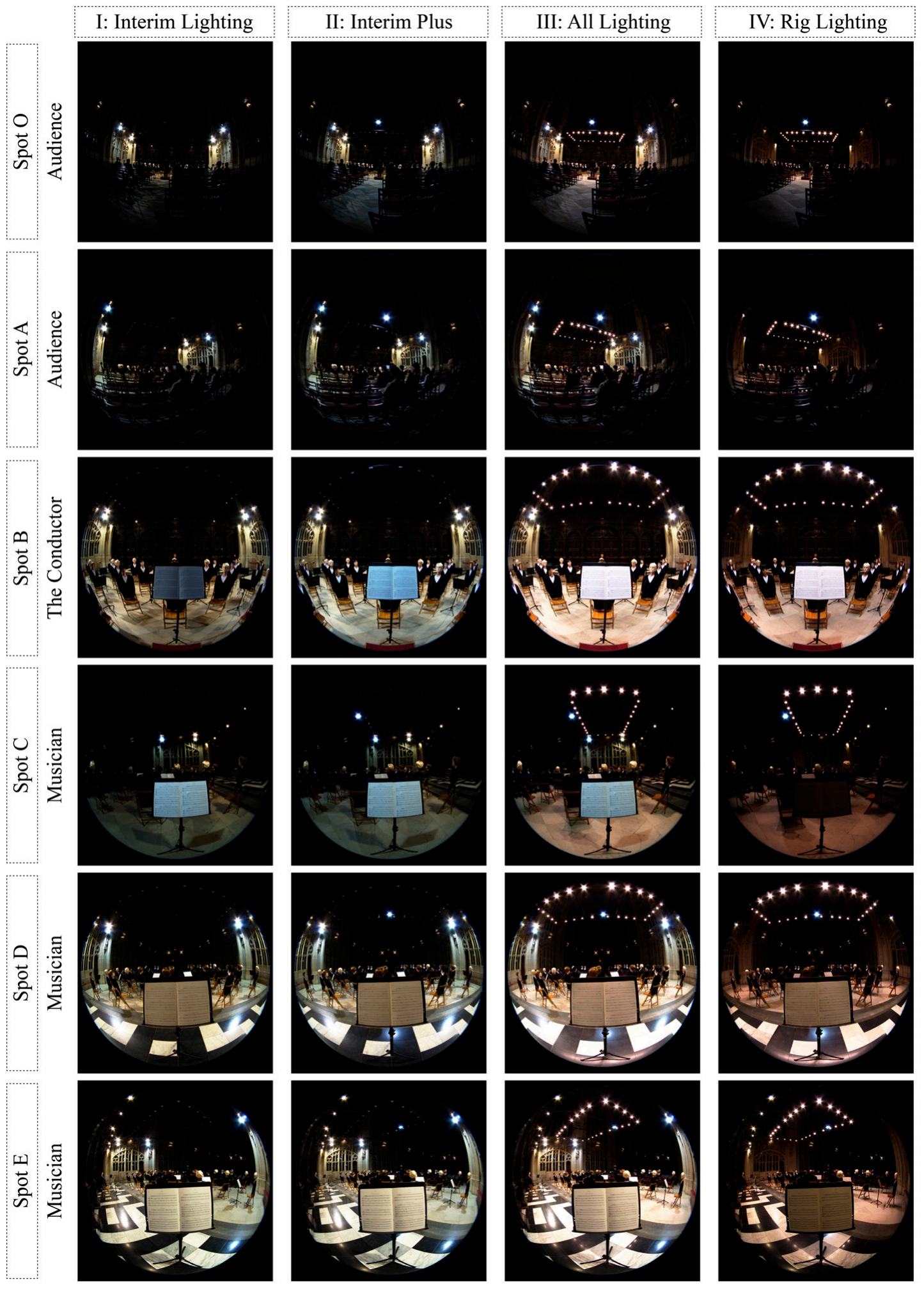


Figure 3. Presentation sequences of the light settings

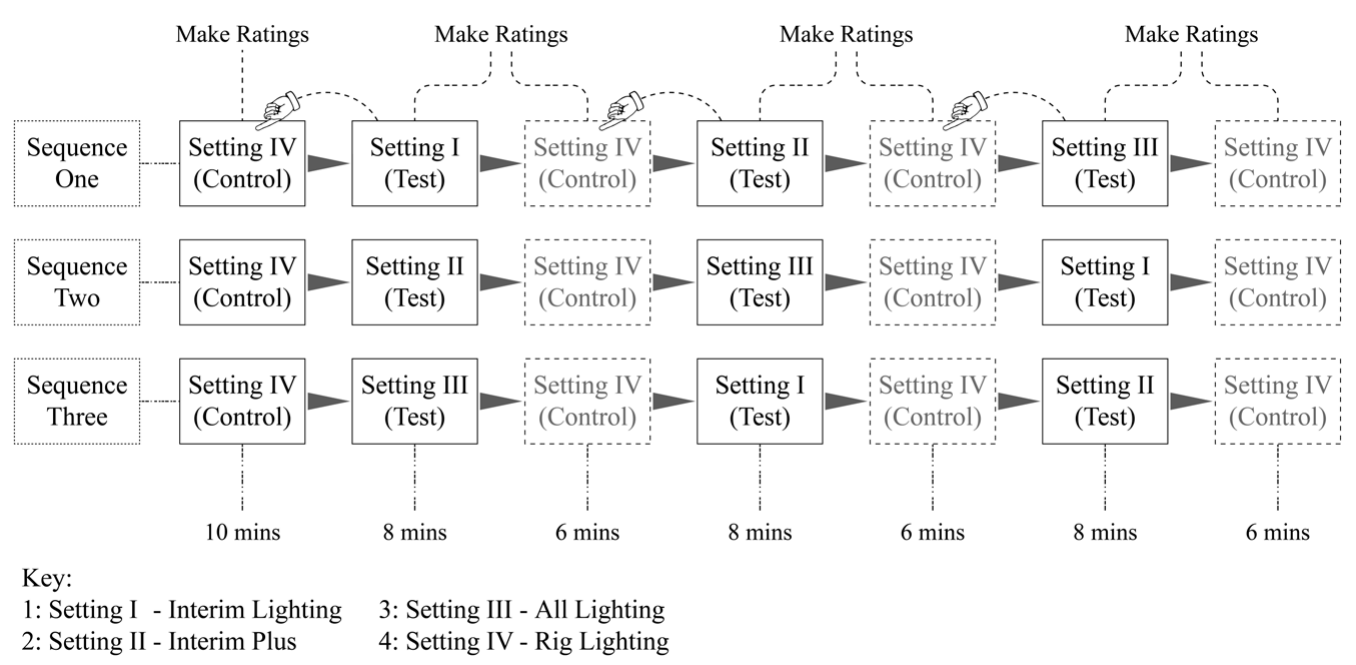

Any musician participants were then assigned to Spot B, C, D or E; nonmusician participants were allocated to Spot O or A (Figure 2). Each run of the experiment was 50 minutes. For logistical and practical reasons, two experimental sessions were conducted each evening with the same participants. Upon completing the first session, they were given a five-minute break and then assigned to another spot with a different visual field and asked to repeat the task. The participants were instructed not to converse with each other throughout the experiment. Altogether, there were 26 sessions using 13 six-person groups.

The participants were asked to compare the four light settings (Figure 5). The chapel was initially set to Setting IV (i.e. control condition) such that the participants could begin to adapt to the luminous context before they started the session. Each test setting was presented followed by a return to the control setting, enabling the participants make their objective and subjective comparisons between the test and control settings (Figure 3). Since there were three test settings, the number of possible sequences was six. However, there were two sessions each evening and the variation in the measurements was rather small as a result of the limited range of lighting conditions 
studied, and thus having three different sequences was deemed desirable. To eliminate possible order effects, the presentation of each setting was restricted to 8 minutes, where the participants were instructed to start rating only after the first 3 minutes of each display allowing their eyes to adapt before they attempted any rating, and were instructed to use the ratings of the control setting as reference points for evaluating the test settings as a means of experimental control. The questions were exactly the same for each setting. Overall, 26 responses were collected at each viewing position, resulting in a total of 624 responses (4 light settings x 6 viewing positions x 26 responses).

\subsection{Subjective attributes}

An underlying proposition of this study was that occupants' responses change when physical parameters are manipulated. Acoustics studies in auditoriums and our lighting studies in the chapel both concern occupants' concert experience, albeit different types of sensory experiences. Given that similarity, the lists of perceptual attributes devised by Beranek ${ }^{55}$ and Barron ${ }^{56}$ served as a basis for the selection of the subjective attributes studied. The selection was, however, made with reference to the classic visual language used by Flynn ${ }^{25,57}$ and Flynn et al..$^{24,58,59}$ To make a rational and systematic selection, three steps were followed: i) identify relevant acoustics vocabularies; ii) translate the vocabularies into visual language; and iii) justify the selection by referring to the design principles of stage lighting. 
Table 4. Definitions of the selected subjective attributes

\begin{tabular}{|c|c|c|c|}
\hline \multicolumn{2}{|c|}{ Reference } & \multicolumn{2}{|c|}{ Selection } \\
\hline \multicolumn{2}{|c|}{ Subjective attribute of acoustic quality ${ }^{55,56}$} & \multicolumn{2}{|c|}{ Subjective attribute of lighting quality ${ }^{59}$} \\
\hline 1. Clarity & $\begin{array}{l}\text { Perceived definition of sound; } \\
\text { ability to hear the details of } \\
\text { the music }\end{array}$ & $\begin{array}{l}\text { 1. Visual } \\
\text { Clarity }\end{array}$ & $\begin{array}{l}\text { Perceived distinctiveness of } \\
\text { visual details; ability to see } \\
\text { spatial details; ability to see } \\
\text { the performers and/or } \\
\text { audience members; ability to } \\
\text { read the music sheets or } \\
\text { concert programmes }\end{array}$ \\
\hline 2. Liveliness & $\begin{array}{l}\text { Perceived reverberation - } \\
\text { whether an auditorium appears } \\
\text { live or dead }\end{array}$ & $\begin{array}{l}\text { 2. Visual } \\
\text { Uniformity }\end{array}$ & $\begin{array}{l}\text { Spatial distribution of light } \\
\text { patterns to reveal visual } \\
\text { details of interest and } \\
\text { activities }\end{array}$ \\
\hline 3. Balance & $\begin{array}{l}\text { Balance between soft and } \\
\text { strong sound tones; balance } \\
\text { between different sections of } \\
\text { an orchestra }\end{array}$ & $\begin{array}{l}\text { 3. Visual } \\
\text { Balance }\end{array}$ & $\begin{array}{l}\text { Balance between dark and } \\
\text { light; balance between } \\
\text { different parts of the } \\
\text { luminous environment }\end{array}$ \\
\hline 4. Loudness & Relative strength of sound & 4. Brightness & Relative intensity of light \\
\hline 5. Intimacy & $\begin{array}{l}\text { Acoustic involvement with a } \\
\text { performance }\end{array}$ & $\begin{array}{l}\text { 5. Spatial } \\
\text { Intimacy }\end{array}$ & $\begin{array}{l}\text { Impression of extroverted or } \\
\text { introverted activities }\end{array}$ \\
\hline
\end{tabular}

Five acoustic attributes — clarity, liveliness, balance, loudness and intimacy — were considered to be relevant. Based on the meaning and nature of each attribute, such attributes were translated into five visual analogues: visual clarity, visual uniformity, visual balance, brightness and spatial intimacy (Table 4). The key to good stage lighting design is creating selective, atmospheric and dimensional illumination. ${ }^{60,61}$ Further evaluation against these principles was made as a means of justification. It must be reiterated that the attributes were specifically chosen for this study. The selection therefore should not be regarded as definitive; rather it should be viewed as part of the evaluation process. 
Figure 4. Sample questionnaire used by audience participants

Light Setting: I

Role: An audience member

Position: Spot A

1) VISUAL CLARITY

\begin{tabular}{ll|lll}
\hline A. How well can you read the programme? & $\begin{array}{l}\text { Very } \\
\text { poor }\end{array}$ & $\square \square \square \square \square \square$ & $\begin{array}{l}\text { Very } \\
\text { well }\end{array}$ \\
\hline B. $\quad \begin{array}{l}\text { How well can you see the facial expressions of } \\
\text { the musicians? }\end{array}$ & $\begin{array}{l}\text { Very } \\
\text { poor }\end{array}$ & $\square \square \square \square \square \square$ & $\begin{array}{l}\text { Very } \\
\text { well }\end{array}$ \\
\hline C. How would you rate this lighting environment? & Hazy & $\square \square \square \square \square \square \square$ & Clear \\
\hline
\end{tabular}

2) DISTRIBUTION OF LIGHT

\begin{tabular}{|c|c|c|c|c|}
\hline & & \multirow{3}{*}{$\begin{array}{l}\text { Not } \\
\text { at all }\end{array}$} & & \\
\hline & conductor? & & 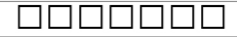 & \multirow{2}{*}{ Definitely } \\
\hline & ii. musicians? & & 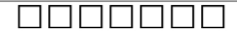 & \\
\hline
\end{tabular}

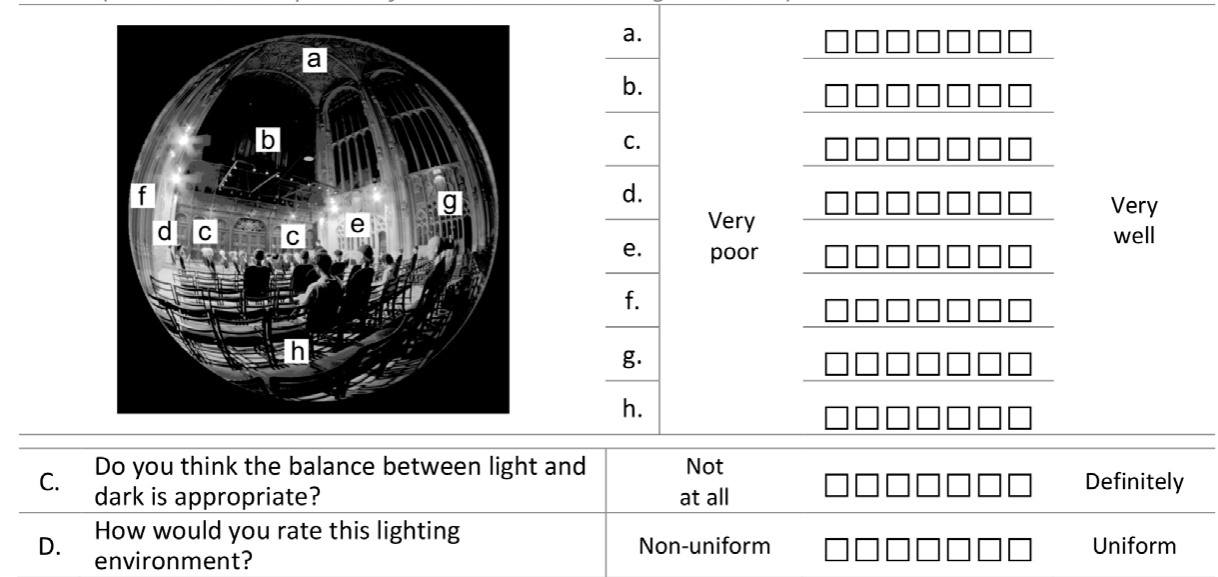

\section{3) SPATIALITY}

\begin{tabular}{|c|c|c|c|c|}
\hline A. & $\begin{array}{l}\text { How appropriate is this visual environment } \\
\text { for your enjoyment of the concert? }\end{array}$ & $\begin{array}{c}\text { Very } \\
\text { inappropriate }\end{array}$ & मロ $\square \square \square \square$ & $\begin{array}{c}\text { Very } \\
\text { appropriate }\end{array}$ \\
\hline \multirow{4}{*}{ B. } & \multirow{4}{*}{$\begin{array}{l}\text { How would you rate this lighting } \\
\text { environment? }\end{array}$} & $\operatorname{Dim}$ & ㅁㅁㅁ & Bright \\
\hline & & Confined & 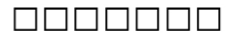 & Spacious \\
\hline & & Intimate & ㅁㅁㅁㅁ & Public \\
\hline & & Uncomfortable & ㅁㅁㅁ & Comfortable \\
\hline
\end{tabular}

\section{4) OVERALL IMPRESSION}

\begin{tabular}{l|ccc}
\hline A. How satisfied are you with the overall & $\begin{array}{c}\text { Very } \\
\text { lighting experience? }\end{array}$ & $\square \square \square \square \square \square \square$ & $\begin{array}{c}\text { Very } \\
\text { satisfied }\end{array}$ \\
\hline
\end{tabular}

\section{5) FURTHER COMMENTS}

*To signal that you have completed this section, please place the 'Done!' sign on the chair to your right.*

\subsection{Questionnaires}

The definitions of the selected subjective attributes laid the foundation for designing the questionnaire. The questionnaire comprised three main sections dealing with visual clarity, the distribution of light and spatiality (Figure 4). Ratings of these 
Figure 5. An experimental session

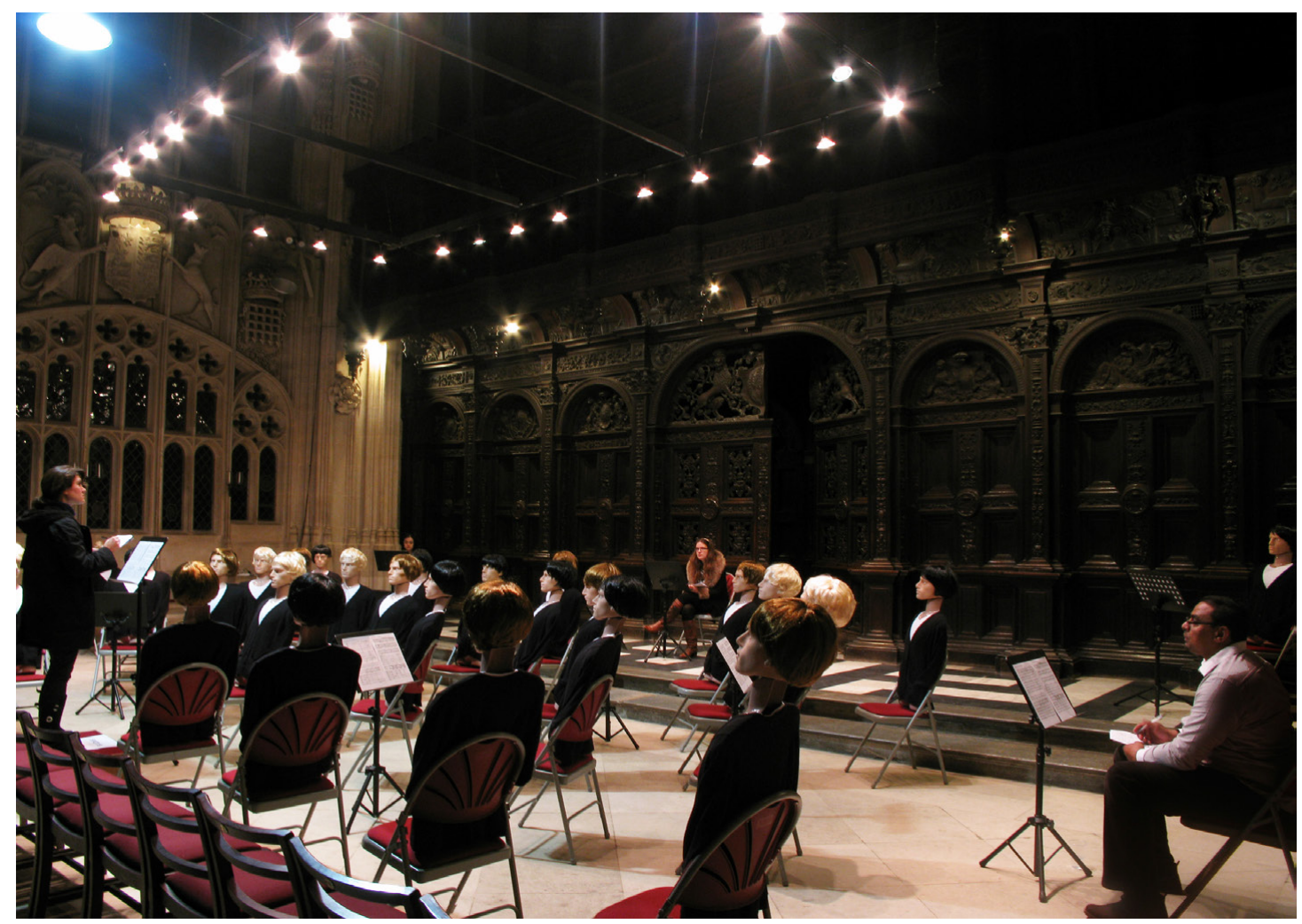

attributes under different lighting arrangements were collected using a series of sevenpoint Likert scales. Previous lighting studies have usually relied on semantic differential scales, but this questionnaire was a combination of factual, semi-subjective and subjective questions. The questions were tailored to each type of occupant audience member, the conductor or musician — to reflect their different luminance requirements. ${ }^{62}$

The length of the questionnaire was limited to one page for each lighting condition in order to keep the participants motivated as they were assisting with the experiments in the evening after a full working day (Figure 5). To make the questionnaires less wordy, the question about the luminous distribution was accompanied by an image in an effort to promote more specific responses. Space for unstructured comments was provided to elicit additional responses. 


\subsection{Physical measurements}

Detailed physical measurements of the light were made at all six positions using HDR imaging techniques. The image processing operations were performed using the Radiance lighting simulation system ${ }^{46}$ in a Linux environment, and using Matlab ${ }^{63}$. Measuring procedures have been presented previously. ${ }^{54}$ We processed and analysed the images and photometric data in relation to the observer's visual field, aiming to provide a comprehensive mathematical and spatial analysis of light for the chapel. For this to be achieved, we adopted image zoning and abstraction techniques (Figure 6 and Figure 7):

- Using binary masks, the images were partitioned based on the structure of the visual field. The masks defined regions of the entire visual field assuming binocular vision with left and right monocular fields. The extent of these regions was assumed based on the perimeter chart of a binocular visual field. ${ }^{64,65}$

- The visual acuity in any region depends on the density and distribution of rod and cone cells in the retina, and is expressed as a function of the visual angle subtended in the eye. To address this we created a second set of masks defining the regions from the foveola between $0^{\circ}$ and $90^{\circ}$. Unlike an actual visual image projected onto the retina, a photographic image does not truly reflect the change of acuity in the visual field. To overcome this limitation, a new index — termed relative visual acuity — was formulated to understand the physical measurements collected in this study. The index was defined relative to the visual angle subtended at the foveola (Table 6). ${ }^{66}$ The further away from the foveola, the smaller the value of the index. Using Matlab scripts, the photometric data were then weighted by multiplying the luminance and pixel values with the index, as though they had been 'resolved' by the eye. 
- A separate set of masks was created to extract target and background luminances from the images.

- To describe the shape and extent of light patterns, the images were converted into false-colour maps, relative luminance maps and two-level greyscale maps. Relative luminance (RL) is defined as a ratio of spot luminance to the maximum luminance of a visual field expressed as a percentage. Given the forgiving nature of seeing, the luminance values of bright sources were isolated from the calculation. The false-colour images retain most of the visual details, whereas the two-level greyscale images are the most abstract form of the three maps. Not only does image abstraction make it easier to describe the light patterns, but also it reflects more closely the fact that the perception of visual details is often omitted during the process of field scanning before fixation.

Although an image can be partitioned into many small segments, that was considered unnecessary here because the boundaries are in fact rather arbitrary. However, clearly defined partitioning is important to enable the development of a reproducible method for describing a visual scene. Having considered the classic theorems and equations for the quantification of light, 22 functions were derived and categorised into 4 groups: visual acuity, uniformity, brightness and light pattern. These were computed for each light setting and location. Grouping and selecting explanatory variables have been reported elsewhere. ${ }^{62}$ This paper focuses on the variables listed in Table 5. 
Table 5. Objective measures selected to describe visual acuity, uniformity, brightness and light pattern

\begin{tabular}{|c|c|c|}
\hline Group & Measure & Description \\
\hline \multirow[t]{6}{*}{$\begin{array}{l}1 . \text { Visual } \\
\text { acuity }\end{array}$} & TLum Sheets avg & $\begin{array}{l}\text { Average target (music sheets or programmes) } \\
\text { luminance value }\end{array}$ \\
\hline & BkLum -Sheets avg & $\begin{array}{l}\text { Average background luminance value: } \\
\text { Luminance distribution of a full visual field } \\
\text { minus that of the music sheets or programmes }\end{array}$ \\
\hline & TLum Stage avg & Average target luminance value on the stage \\
\hline & BkLum -Stage avg & $\begin{array}{l}\text { Average background luminance value: } \\
\text { Luminance distribution of a full visual field } \\
\text { minus that of the stage }\end{array}$ \\
\hline & VA sheets & $\begin{array}{l}\text { Visual acuity: Ability to discern fine details of } \\
\text { the music sheets or programmes } \\
\text { (TLum Sheets avg:BkLum -Sheets avg) }\end{array}$ \\
\hline & VA Stage & $\begin{array}{l}\text { Visual acuity: Ability to discern fine details on } \\
\text { the stage } \\
\text { (TLum Stage avg:BkLum -Stage avg) }\end{array}$ \\
\hline \multirow[t]{3}{*}{ 2. Uniformity } & $\left(\left(\mathrm{LLM}_{\mathrm{avg}}+\mathrm{LRM}_{\mathrm{avg}}\right) / 2\right): \mathrm{LB}_{\text {avg }}$ & $\begin{array}{l}\text { A ratio of average luminance seen through the } \\
\text { left and right monocular fields to average } \\
\text { luminance seen through the binocular field }\end{array}$ \\
\hline & $\mathrm{LLM}_{\mathrm{avg}}: \mathrm{LRM}_{\mathrm{avg}}$ & $\begin{array}{l}\text { A ratio of average luminance seen through the } \\
\text { left monocular field to that seen through the } \\
\text { right monocular field }\end{array}$ \\
\hline & $\mathrm{LLM}_{\text {std }}: \mathrm{LRM}_{\text {std }}$ & $\begin{array}{l}\text { A ratio of the standard deviation of luminance } \\
\text { seen through the left monocular field to that } \\
\text { seen through the right monocular field }\end{array}$ \\
\hline \multirow[t]{4}{*}{ 3. Brightness } & $\mathrm{L}_{\mathrm{var}}$ & Variation of luminance of a full visual field \\
\hline & $\mathrm{L}_{\text {avg }}$ & Average luminance of a full visual field \\
\hline & $\mathrm{RL}_{\text {avg }}$ & Average of the relative luminance values \\
\hline & $\mathrm{RL}_{\text {std }}$ & $\begin{array}{l}\text { Standard deviation of the relative luminance } \\
\text { values }\end{array}$ \\
\hline \multirow[t]{4}{*}{$\begin{array}{l}\text { 4. Light } \\
\text { pattern }\end{array}$} & Area $_{\text {Light patches }}$ & $\begin{array}{l}\text { After binarising a coloured image into a two- } \\
\text { level greyscale image based on its mean } \\
\text { intensity value, this variable is obtained by } \\
\text { counting the total number of white pixels of the } \\
\text { two-level greyscale image. }\end{array}$ \\
\hline & Euler number & $\begin{array}{l}\text { Calculated by pixel connectivity, this variable } \\
\text { computes the number of regions detected } \\
\text { within an image. The higher the Euler number } \\
\text { (i.e. light patches), the more scattered is the } \\
\text { luminance field. }\end{array}$ \\
\hline & Light:Dark & $\begin{array}{l}\text { Total number of white and black pixels of a } \\
\text { two-level greyscale image }\end{array}$ \\
\hline & Perimeter & $\begin{array}{l}\text { Total length of the outer edges around the } \\
\text { white areas of a two-level greyscale image }\end{array}$ \\
\hline
\end{tabular}


Figure 6. Image zoning techniques: Visual-field masking and spatial masking (available in colour in online version)

a) Intensity image partitioned in relation to the structure of the visual field (Spot E)

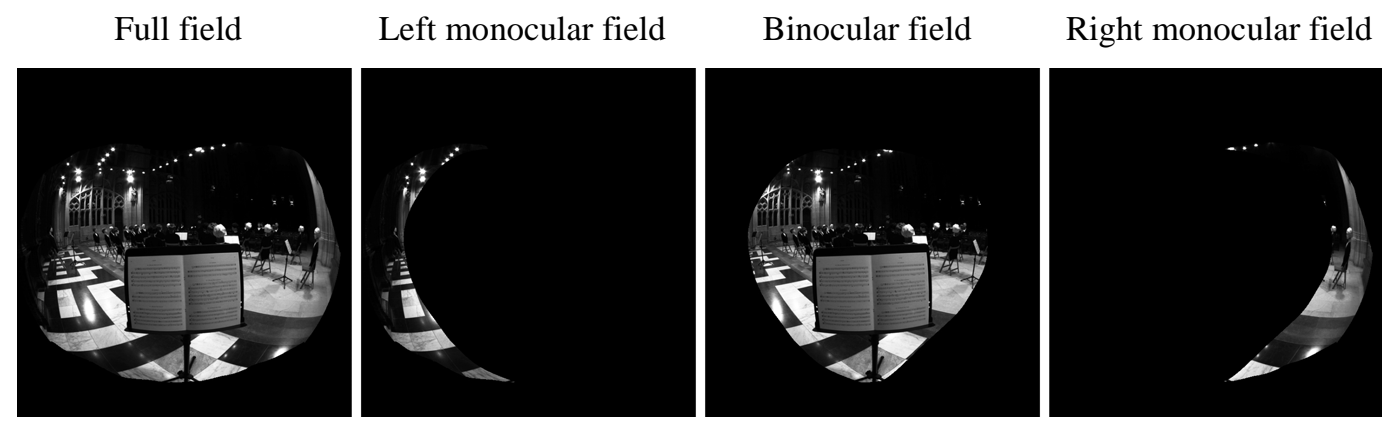

b) Intensity image partitioned in relation to the visual angle subtended at the eye (Spot E)

$0^{\circ}$ and $20^{\circ}$
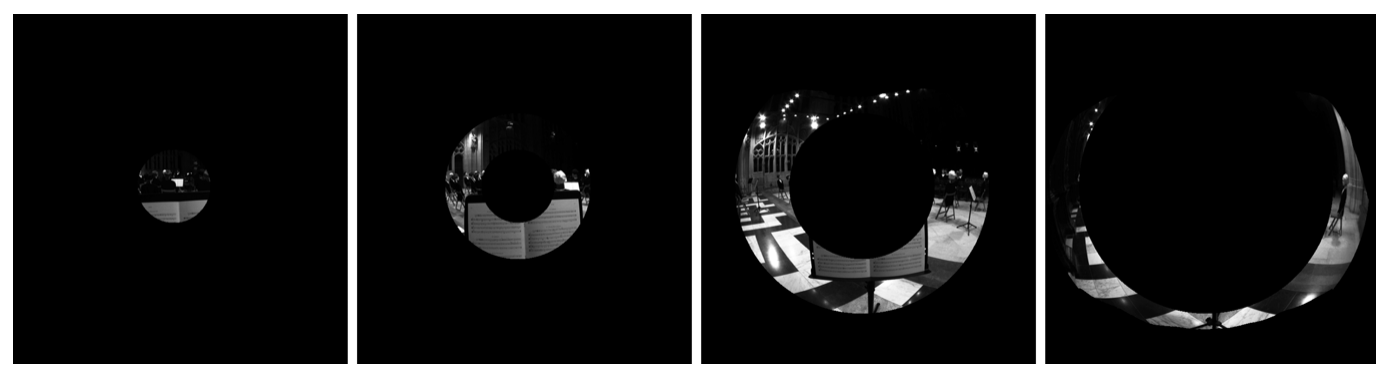

c) Binary masks for the extraction of target (top) and background (bottom) luminances (Spot B)

Original image
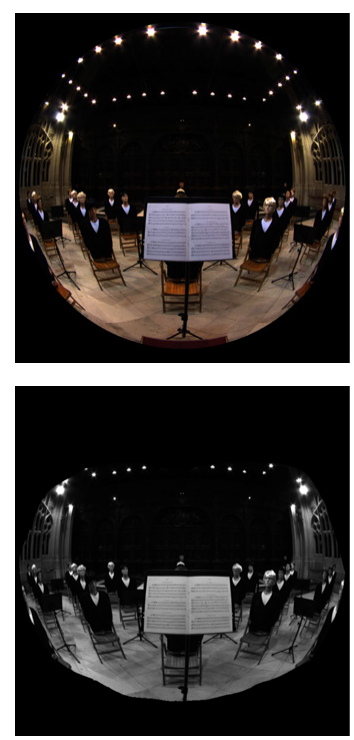

Music sheets
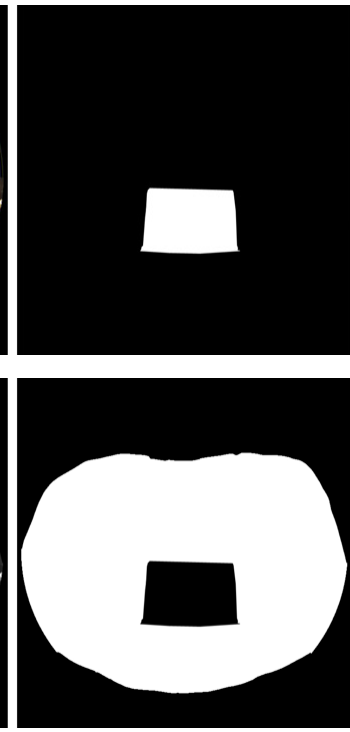

Musicians
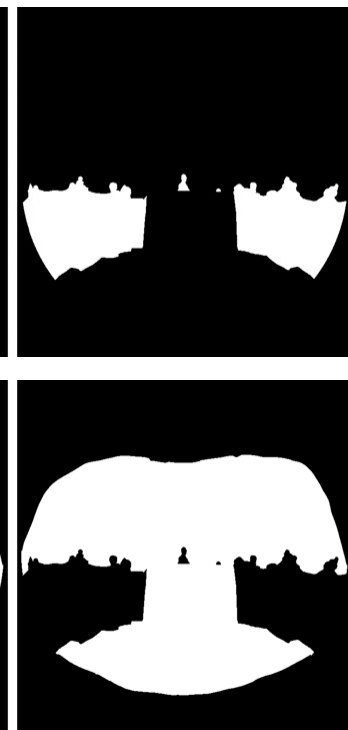

Performance stage
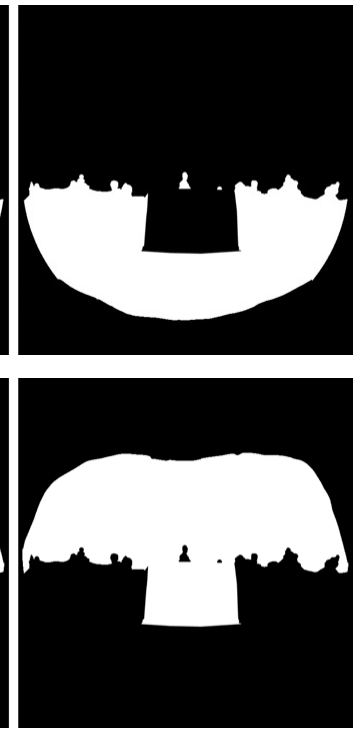
Figure 7. Image abstraction: Relative luminance mapping and two-level greyscale mapping techniques (available in colour in online version)

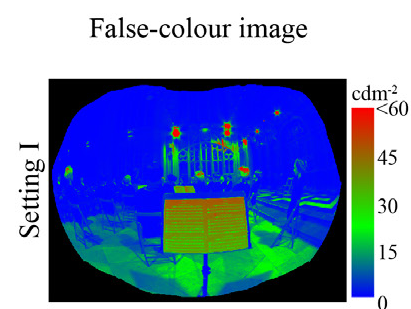

Relative luminance map

Relative luminance map
(with bright patches only)
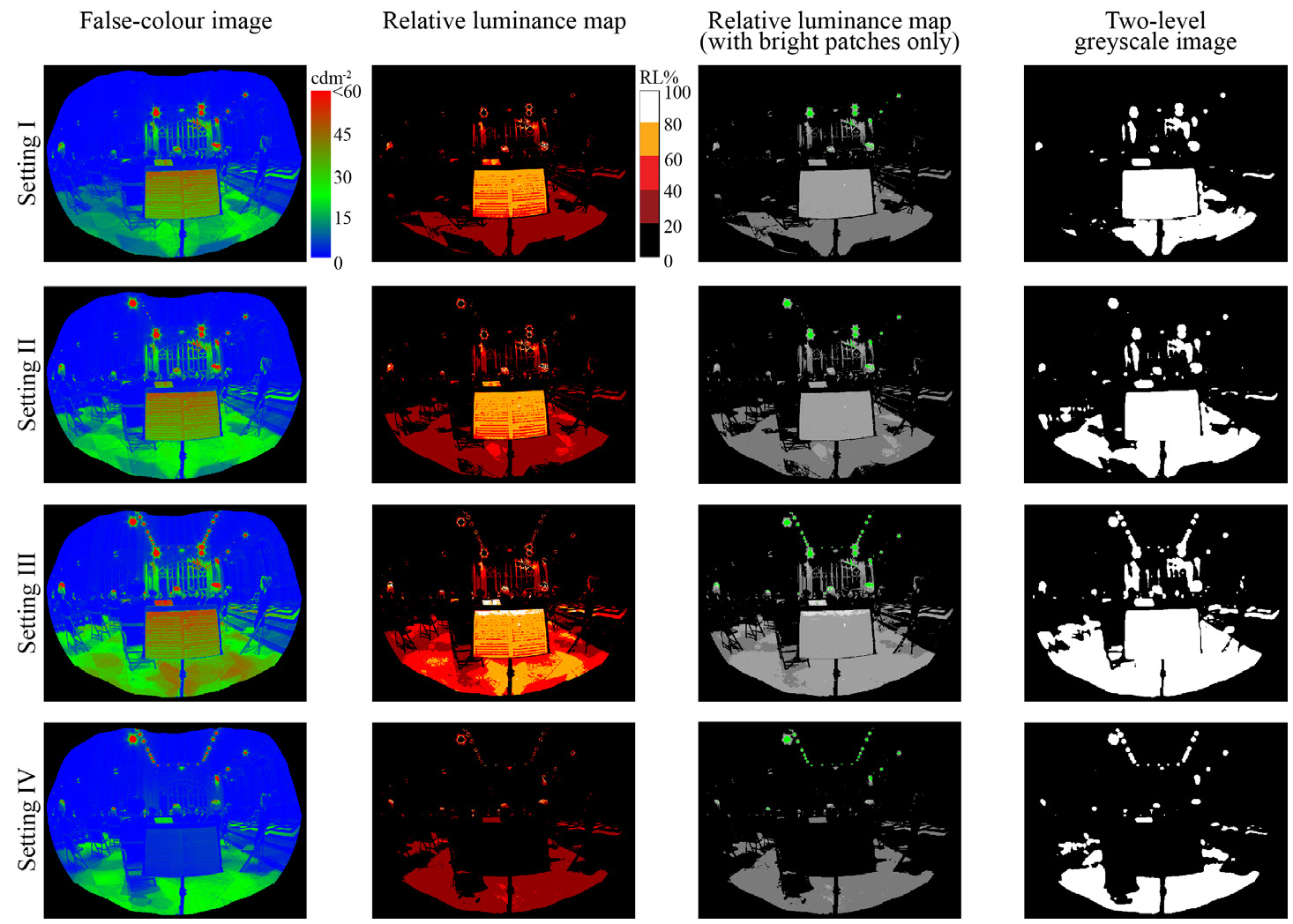

Table 6. Visual angles subtended at the eye and relative visual acuity

\begin{tabular}{ccccc}
\hline Degree from foveola & $\begin{array}{c}\text { Visual angle subtended } \\
\text { at the eye (arc-minute) }\end{array}$ & Relative visual acuity \\
\hline $0^{\circ}$ & $0.7^{\prime}$ & $0.7^{\prime} / 0.7^{\prime}$ & $=$ & 1 \\
\hline $0^{\circ}$ & $0.7^{\prime}$ & $0.7^{\prime} / 10^{\prime}$ & $=$ & 0.07 \\
$20^{\circ}$ & $10^{\prime}$ & & & \\
\hline $20^{\circ}$ & $10^{\prime}$ & $0.7^{\prime} / 27.5^{\prime}$ & $=$ & 0.025 \\
$40^{\circ}$ & $27.5^{\prime}$ & & & \\
\hline $40^{\circ}$ & $27.5^{\prime}$ & $0.7^{\prime} / 100^{\prime}$ & $=$ & 0.007 \\
$70^{\circ}$ & $100^{\prime}$ & & & \\
\hline $70^{\circ}$ & $100^{\prime}$ & $0.7^{\prime} /$ Unmeasurable & $=$ & 0 \\
$90^{\circ}$ & Unmeasurable & & & \\
\hline
\end{tabular}




\section{Results and discussions}

\subsection{Structure of the field experiment}

Ordinal logistic regression was applied to determine the likelihood that the subjective ratings were influenced by the order of experimental sessions. The result confirms that the order was not significantly associated with any clear tendency in the responses (sig. $=0.279)$. In addition, there is no consistent agreement in the standard deviation of the scores observed among the sessions, and thus rejecting the hypothesis that the experiment's structure affected the overall impressions. A limitation is that this study did not use all the six possible sequences and thus order effects could not be alleviated fully. In hindsight, using all the sequences would counterbalance potential order effects; having the control setting re-evaluated each time it was presented would make an evaluation of order effects possible.

\subsection{Construct validity of the questionnaire}

To validate the construct of the questionnaire and to assess the internal reliabilities of the responses in relation to the subjective attributes, Cronbach's alpha coefficients $(\alpha)$ were calculated. We found that the overall internal reliability was acceptable at all of the positions, with $\alpha$ s ranging from 0.86 to 0.93 .

The 'Visual Clarity' questions were found to have a good reliability, with as ranging from 0.89 to 0.96 . The reliability for the 'Distribution of Light' and 'Spatiality' sections was satisfactory, except at Spot A where the coefficient for 'Distribution of Light' fell below 0.5. The Non-uniform/Uniform and Dim/Bright scales were considered as independent scale for rating Visual Uniformity and Brightness. The reason for this is that when Non-uniform/Uniform was correlated with the factual 
questions for 'Distribution of Light', the coefficient fell below the cut-off point, indicating a very poor level of agreement among the responses. An improvement was noted, however, when the factual questions were correlated with Light/Dark balance. Yet, the coefficients for spots A ( $\alpha=0.44)$ and $\mathrm{E}(\alpha=0.43$ ) were still below the cut-off point. A plausible explanation for the inconsistency is that the visual scenes at these positions were rather asymmetric compared to the others, and that could have made the assessment less straightforward.

For Brightness and Spatial Intimacy, the Dim/Bright scale was found to be poorly correlated with Inappropriate/Appropriate (average $\alpha=0.33$ ) and with Uncomfortable/Comfortable (average $\alpha=0.38$ ). Although the coefficients for Confined/Spacious and Intimate/Public were considered as acceptable (average $\alpha=$ 0.75), the reliability could be further improved by coupling Dim/Bright with Confined/Spacious (average $\alpha=0.77$ ). To avoid double counting, therefore, Intimate/Public was considered as a single scale to account for Spatial Intimacy. The scales for Inappropriate/Appropriate and Uncomfortable/Comfortable exhibited good internal reliability, with $\alpha$ coefficients ranging from 0.70 to 0.90 . This implies that those scales may reflect similar patterns in responses. With this in mind, those two scales were grouped as an additional subjective predictor termed Appropriateness/Comfort.

\subsection{Ordered logistic regression}

Ordered logistic regression is a generalised linear modelling approach which not only relaxes the assumption, but also captures nonlinear relationships. ${ }^{31}$ It is specifically designed to deal with categorical data (i.e. those collected for this study) and should give a unified view of the subjective and objective data. 
The validity of the ordered models was assessed by a series of model-fitting, goodness-of-fit and proportional odds tests (Table 7). The ordered models fit the data well for Visual Clarity (chi-square $=45.43$ to 230.47), and moderately well for Brightness (chi-square $=58.58$ to 177.90) and Spatial Intimacy (chi-square $=38.30$ to 182.30). The poorest fit is for the Visual Balance data (chi-square $=4.89$ to 20.54) and for Appropriateness/Comfort (chi-square $=1.51$ to 43.51). It is worth noting that of the four sets of analyses, the models for All Occupants appear to have the largest chi-square values. This may however arise from the larger number of degrees of freedom involved. It does not necessarily mean that increasing the number of responses would lead to a greater improvement in the general model. 
Table 7. Fit statistics for the ordered logistic regressions by occupant's role (Independent variables $=$ Objective measures)

\begin{tabular}{|c|c|c|c|c|c|c|c|c|c|c|}
\hline \multirow{2}{*}{\multicolumn{2}{|c|}{$\begin{array}{l}\text { Subjective } \\
\text { attribute } \\
\text { (a) }\end{array}$}} & \multicolumn{3}{|c|}{ Model Fitting } & \multicolumn{3}{|c|}{ Goodness-of-fit } & \multicolumn{3}{|c|}{ Proportional Odds } \\
\hline & & $\begin{array}{l}\text { Chi- } \\
\text { square } \\
\text { (b) (e) }\end{array}$ & $\begin{array}{l}\text { Degrees } \\
\text { of } \\
\text { freedom }\end{array}$ & Sig. & $\begin{array}{l}\text { Chi- } \\
\text { square } \\
\text { (c) (e) }\end{array}$ & $\begin{array}{l}\text { Degrees } \\
\text { of } \\
\text { freedom }\end{array}$ & Sig. & $\begin{array}{l}\text { Chi- } \\
\text { square } \\
\text { (d) (f) }\end{array}$ & $\begin{array}{l}\text { Degrees } \\
\text { of } \\
\text { freedom }\end{array}$ & Sig. \\
\hline \multirow{4}{*}{ 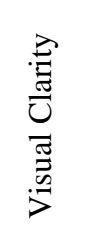 } & $\mathrm{Am}$ & $83.10 * * *$ & 4 & 0.00 & $18.40^{\mathrm{ns}}$ & 31 & 0.96 & $15.63^{\text {ns }}$ & 16 & 0.48 \\
\hline & Co & $45.43^{* * *}$ & 2 & 0.00 & $21.68^{n s}$ & 13 & 0.06 & $11.34^{\text {ns }}$ & 8 & 0.18 \\
\hline & $\mathrm{Mu}$ & $78.15^{* * *}$ & 6 & 0.00 & $41.59^{\mathrm{ns}}$ & 38 & 0.32 & $14.62^{\mathrm{ns}}$ & 18 & 0.69 \\
\hline & All & $230.5^{* * *}$ & 12 & 0.00 & $87.65^{\text {ns }}$ & 103 & 0.86 & $59.68^{\mathrm{ns}}$ & 48 & 0.12 \\
\hline \multirow{4}{*}{ 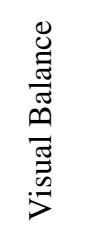 } & $\mathrm{Am}$ & $12.68^{* *}$ & 4 & 0.01 & $\underline{51.24^{* *}}$ & 31 & 0.01 & $\underline{37.78^{* * *}}$ & 16 & 0.00 \\
\hline & Co & $10.71^{* *}$ & 2 & 0.01 & $11.43^{\mathrm{ns}}$ & 10 & 0.33 & $5.62^{\mathrm{ns}}$ & 6 & 0.47 \\
\hline & $M u$ & $4.89^{n s}$ & 5 & 0.43 & $\underline{59.98^{*}}$ & 39 & 0.02 & $21.41^{\text {ns }}$ & 15 & 0.12 \\
\hline & All & $20.54^{*}$ & 10 & 0.03 & $\underline{171.6^{* * *}}$ & 105 & 0.00 & $46.70^{\mathrm{ns}}$ & 40 & 0.22 \\
\hline \multirow{4}{*}{ 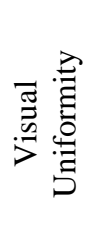 } & Am & $32.67^{* * *}$ & 3 & 0.00 & $39.40^{\mathrm{ns}}$ & 32 & 0.17 & $\underline{25.60^{* *}}$ & 12 & 0.01 \\
\hline & Co & $20.37^{* * *}$ & 2 & 0.00 & $7.16^{\mathrm{ns}}$ & 10 & 0.71 & $2.34^{\mathrm{ns}}$ & 6 & 0.89 \\
\hline & $\mathrm{Mu}$ & $18.77^{* * *}$ & 5 & 0.00 & $54.15^{n s}$ & 50 & 0.32 & $29.40^{\text {ns }}$ & 20 & 0.08 \\
\hline & All & $61.50^{* * *}$ & 10 & 0.00 & $124.64^{\mathrm{ns}}$ & 105 & 0.09 & $\underline{63.97^{* *}}$ & 40 & 0.01 \\
\hline \multirow{4}{*}{ 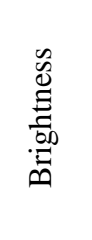 } & Am & $99.46^{* * *}$ & 3 & 0.00 & $36.38^{\mathrm{ns}}$ & 39 & 0.59 & $14.80^{\text {ns }}$ & 15 & 0.47 \\
\hline & Co & $58.58^{* * *}$ & 2 & 0.00 & $8.69^{\mathrm{ns}}$ & 10 & 0.56 & $8.65^{\text {ns }}$ & 6 & 0.20 \\
\hline & $\mathrm{Mu}$ & $105.2^{* *}$ & 5 & 0.00 & $60.75^{n s}$ & 50 & 0.14 & $20.02^{\text {ns }}$ & 20 & 0.46 \\
\hline & All & $177.9^{* * * *}$ & 8 & 0.00 & $\underline{212.9^{* * *}}$ & 130 & 0.00 & - & 40 & - \\
\hline \multirow{4}{*}{ 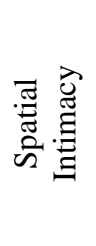 } & $\mathrm{Am}$ & $84.98^{* * *}$ & 3 & 0.00 & $37.69^{\mathrm{ns}}$ & 39 & 0.53 & $\underline{30.63^{* *}}$ & 15 & 0.01 \\
\hline & Co & $38.30^{* * *}$ & 3 & 0.00 & $9.86^{\mathrm{ns}}$ & 12 & 0.63 & $12.82^{\text {ns }}$ & 12 & 0.38 \\
\hline & $\mathrm{Mu}$ & 83.17 $7^{* * *}$ & 5 & 0.00 & $64.31^{\mathrm{ns}}$ & 50 & 0.08 & $22.96^{\mathrm{ns}}$ & 20 & 0.29 \\
\hline & All & $182.3^{* * *}$ & 8 & 0.00 & $145.6^{\mathrm{ns}}$ & 130 & 0.17 & $59.86^{\text {ns }}$ & 40 & 0.02 \\
\hline \multirow{4}{*}{ 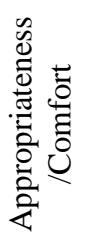 } & $A m$ & $1.51^{n s}$ & 4 & 0.83 & $30.96^{n s}$ & 38 & 0.78 & $25.30^{n s}$ & 20 & 0.19 \\
\hline & Co & $17.68^{* * *}$ & 3 & 0.00 & $17.00^{\mathrm{ns}}$ & 12 & 0.15 & $20.58^{\text {ns }}$ & 12 & 0.06 \\
\hline & $M u$ & $3.58^{n s}$ & 4 & 0.47 & $\underline{85.31^{*}}$ & 62 & 0.03 & $33.02^{\text {ns }}$ & 20 & 0.03 \\
\hline & All & $43.51^{* * *}$ & 11 & 0.00 & $150.87^{\text {ns }}$ & 127 & 0.07 & $\underline{96.62^{* * *}}$ & 55 & 0 \\
\hline
\end{tabular}

(a) 'Am' = Audience Members; 'Co' = The Conductor; 'Mu' = Musicians; 'All' = All Occupants

(b) Difference between the maximised log-likelihood for the fitted model and

that for the general model $=\left(-2\left(\mathrm{~L}_{0}-\mathrm{L}_{1}\right)\right)$

(c) Pearson's $\chi^{2}$

(d) Difference between the maximised log-likelihood for the null model and

that for the fitted model $=\left(-2\left(\mathrm{Ln}_{\mathrm{n}}-\mathrm{L}_{\mathrm{f}}\right)\right)$

(e) $(* * *) p \leq .001 ;(* *) p \leq .01 ;(*) p \leq .05 ;\left({ }^{*}\right) p>.05$; underscore indicates unsatisfactory model fit

(f) $\left.\left({ }^{* * *}\right) p \leq .001 ;\left(^{* *}\right) p \leq .01 ;{ }^{\text {ns }}\right) p>.01$; underscore indicates different slope coefficient for each of the odds

(g) Bold text indicates a model which passes the model-fitting, goodness-of-fit and proportional odds tests. 
The results of the proportional odds tests indicate that all of the models for Visual Clarity satisfy the assumption $(p>0.01)$. That is not the case, however, for Visual Balance, Visual Uniformity, Brightness, Spatial Intimacy or Appropriateness/Comfort. A closer examination of the statistics shows that the unsatisfactory results for Visual Balance, Visual Uniformity and Spatial Intimacy are all related to Audience Members. This outcome is rather unanticipated, in part because none of those models failed to meet the proportional odds assumption when analysing by viewing position. Two plausible explanations for the poor fit suggest themselves. First, one of the spots for Audience Members showed only marginal significance in each case, weakening the model when the data were pooled. Then, more degrees of freedom also induces greater variability among the data, constraining the models' fit.

Visual Clarity has the best average model fit $(p=0.450$, standard deviation $(\mathrm{S} . \mathrm{D})=0.209$.$) , while that of Appropriateness/Comfort was the least satisfactory (p=$

0.093, S.D. $=0.069)$. The attributes that ranked in between are Brightness, Visual Uniformity, Spatial Intimacy and Visual Balance. For Visual Clarity and Brightness, all of the models satisfied all the assumptions; for Visual Uniformity and Spatial Intimacy, the models for the Conductor and Musicians fully met the assumptions; for Visual Balance and Appropriateness/Comfort, however, only the model for the Conductor passed all the tests.

\subsection{Lighting condition effects}

Dummy coding was used to maximise the log-likelihood for the ordered models. The equations served as a means of expressing the possible subjective-objective relationships and as a tool to make general predictions for the chapel. While they were useful, it is necessary to remember that the predictions are indicative only. To study the 
effects of combinations of the measures across the response categories, a set of separate odds ratio calculations was performed. The observed and estimated cumulative probabilities were plotted as a function of each subjective attribute for Audience Members, the Conductor, Musicians and All Occupants (Figure 8). The parallelism of the cumulative curves indicates the difference in perceived quality among the light settings - the more distinctive the spacing of the curves, the greater the influence the change of light settings has on the respective quality. The more skewed the curve, the more likely the responses are weighted towards the higher end of the rating scales.

1. Visual Clarity The lighting condition with all the light fixtures on (Setting III) appears to have higher observed and estimated probabilities in higher ratings than the other settings regardless of the occupant's role. For Audience Members and Musicians, the probabilities in attracting lower ratings appear to be the highest when there were only overhead rig lights and an overhead spotlight (Setting IV), followed by settings without the rig lights (Setting I) and also without the overhead spotlight (Setting II). For the Conductor, however, the condition with peripheral lights only (Setting I) appears to have the highest probabilities of lower ratings, followed by one with overhead lights only (Setting IV) and one without the rig lights (Setting II). Comparing the settings with the two highest probabilities, the Conductor (11.93 times the odds of Setting IV (control)) has the largest difference, whereas Audience Members (0.40 times) and Musicians (0.32 times) have smaller yet similar differences. This implies that the setting with the rig lights tends to be associated with higher ratings from the Conductor but comparatively less from Audience Members and Musicians. 
Figure 8. Cumulative proportion plots for Visual Clarity, Visual Uniformity, Brightness and Spatial Intimacy: Group and overall analysis (available in colour in online version)
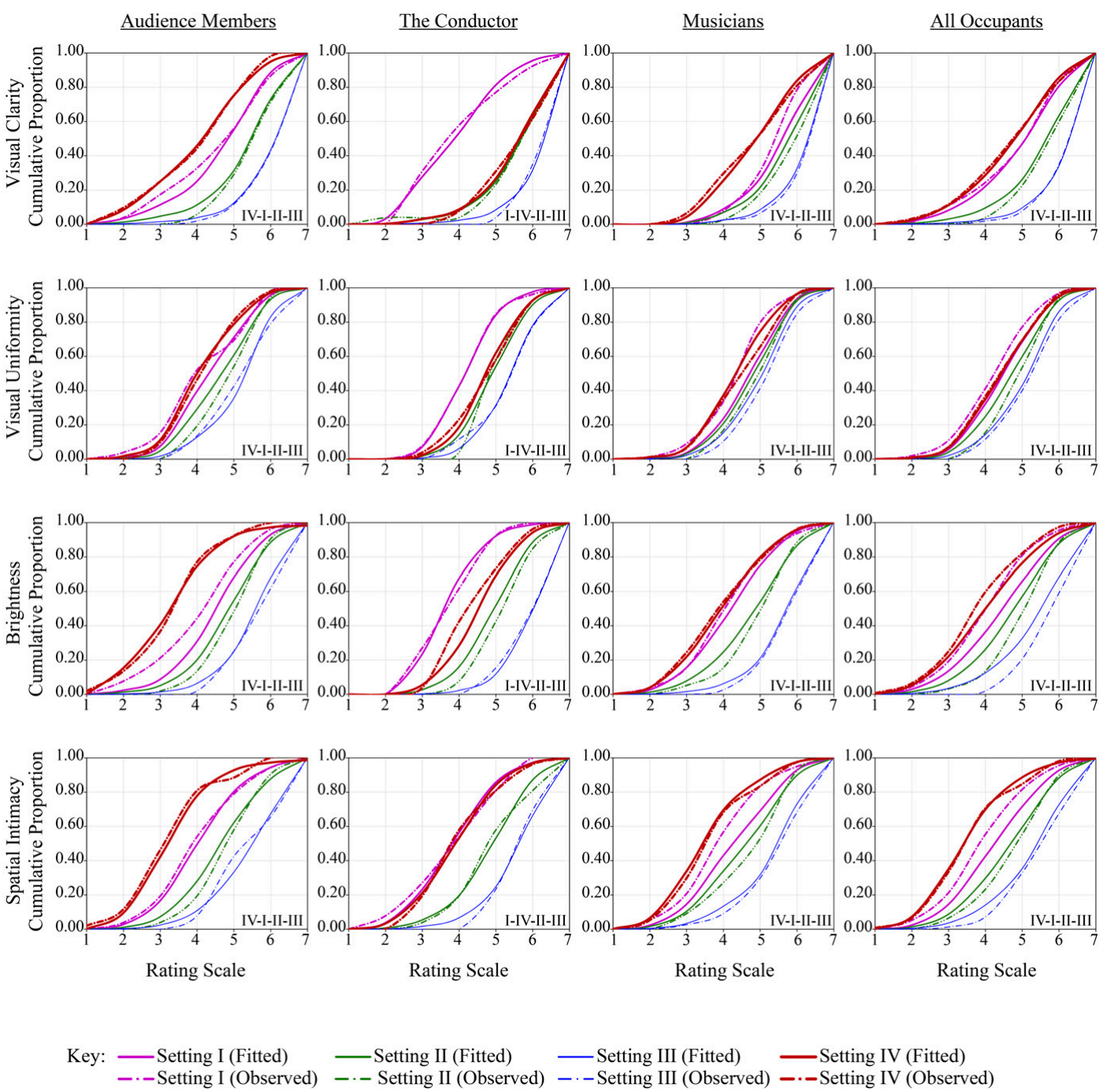

Interestingly, these observations appear to partly contradict Flynn's studies in that he suggested using bright and peripheral lights is key to achieving higher ratings for perceptual clarity. ${ }^{25,57}$ There are two plausible explanations: the complexity of the context studied might have contributed to the difference in observations; our subjects' interpretation of the attribute might be different from their subjects'. The latter has previously been pointed out by Fotios and Atli $^{67}$ as a contested issue in other lighting studies. The higher values of VA stage, VA sheets and LLMavg:LRMavg, and the lower values of $\mathrm{L}_{\mathrm{avg}}$, $\mathrm{R} \mathrm{L}_{\mathrm{std}}$, and Perimeter were consistently associated with better Visual 
Clarity ratings for Audience Members and Musicians. For the Conductor, however, the lower values of VA Sheets and AreaLight patches elicited better ratings. Our findings seem to suggest that occupant's roles and requirements can influence this impression.

2. Visual Uniformity The effects of the variables on the perceptions of Visual Uniformity are more noticeable, as indicated by the wider spread of the curves. The condition with both the peripheral and overhead lights appears to have a higher observed and estimated probability in higher ratings than other settings regardless of the occupant's role. For Audience Members and Musicians, having the overhead rig lights and spotlight (Setting IV) or peripheral lights only (Setting I) appears to attract higher probabilities of lower ratings. For the Conductor, however, having the peripheral lights only (Setting I) seems to impart a greater sense of non-uniformity. A discussion on preferred conditions is beyond the scope of this paper. At the musician positions the higher probabilities for overhead lights are attributable to the lower values of $L_{L} M_{a v g}: L_{R} M_{a v g}, L_{v a r}$ and $R L_{a v g}$. And at the conductor position the higher probabilities for peripheral lights only are attributable to the higher values of Euler number and $\left(\left(\mathrm{LLM}_{\mathrm{avg}}+\mathrm{LRM}_{\mathrm{avg}}\right) / 2\right): \mathrm{LB}_{\mathrm{avg}}$.

It is interesting to note that the conductor responses are in partial agreement with Loe et al.'s studies ${ }^{11}$ in that they reported a higher attraction of responses towards non-uniformity for conditions with peripheral lights only. While they observed a moderate correlation between the responses and the average luminance ( $r=0.67, p \leq$ $0.05)$ or the ratio of maximum luminance to average luminance $(r=-0.69, p \leq 0.05)$ obtained within the $40^{\circ}$ horizontal band, this study suggests that the inclusion of two measures, Euler number and $\left(\left(\mathrm{LLM}_{\mathrm{avg}}+\mathrm{LRM}_{\mathrm{avg}}\right) / 2\right): \mathrm{LB}_{\mathrm{avg}}$, produced a stronger correlation $(r=0.48, p \leq 0.001)$ than considering $\mathrm{L}_{\text {avg }}(r=0.36, p \leq 0.01)$ or $\mathrm{RL}_{\mathrm{avg}}(r$ $=0.45, p \leq 0.01)$ alone. Note that the values of these measures were obtained within 
the full extent of the visual field. Yet, the observation does not seem to be true for Audience Members and Musicians, calling the reliability of Loe et al.'s approach into question.

3. Brightness The parallelism of the curves is much clearer for this attribute. Most of the curves are much more widely spaced than those of the other attributes, though the curves for settings with either peripheral lights (Setting I) or overhead lights (Setting IV) lie close together in the case of Musicians, suggesting that a similar brightness impression seems to associate with these two different lighting modes. While the mix of peripheral lights, overhead rig lights and an overhead spotlight (Setting III) has, again, the highest estimated probability in higher ratings in all cases, which seems to be explained consistently by the higher values of $L L M_{\text {std }}: L_{R M}$ std,$R L_{\text {std }}$ and Light:Dark (Audience Members: $r=0.62, p \leq 0.001$; The Conductor: $r=0.68, p$ $\leq 0.001$; Musicians: $r=0.53, p \leq 0.001$ ). However, lower category responses seem to have been under-represented. Although the models for Brightness were considered less satisfactory than those for Visual Clarity and Visual Uniformity, the estimated odds ratios do not differ significantly from the observed ones.

Moreover, the responses appear to agree with Loe et al.'s observations ${ }^{11}$ that a combination of overhead lights and peripheral lights tends to attract responses towards the higher end of the dim-bright scale. They found a strong correlation between the responses and the average luminance obtained within the $40^{\circ}$ band ( $\left.r=0.93, p \leq 0.05\right)$. Contrary to their findings, $\mathrm{L}_{\text {avg }}$ did not appear to be the strongest predictor in this study. This implies that the average luminance obtained within the $40^{\circ}$ band might seem to be a meaningful measure to determine the appearance of lightness in a simple context, but not in a complex setting as examined in this study. 
4. Spatial Intimacy The spread of the curves is almost identical to that observed for Brightness. For the Conductor, however, the curves of the two highest probabilities (settings I and IV) almost overlap. The odds of Setting I are 1.14 times those of Setting IV. For Musicians and All Occupants the curves for Setting I lie closely above that for Setting II. The observations seem to indicate that these settings imparted a similar sense of spatial intimacy. The condition with the overhead rig lights and overhead spotlight (Setting IV) appears to attract the highest estimated probabilities in lower ratings in all cases, except for the Conductor under the condition with peripheral lights only (Setting I). For Audience Members and Musicians, their ratings were inversely associated with the magnitude of the dominant variable $\mathrm{L}_{\mathrm{avg}}$, and Light:Dark for the Conductor: the higher the value, the greater sense of spatial intimacy. But increasing the value of $L L M_{a v g}: L R M_{a v g}$ might strengthen such impression in any case. Both underestimation and overestimation of the responses were observed in most cases. Since the difference between the estimated and observed odds ratios is negligible, the model can thus be considered acceptable. 
Figure 9. Comparison of the Pseudo $R_{N}^{2}$ values for Visual Clarity, Visual Uniformity, Brightness and Spatial Intimacy using the objective measures

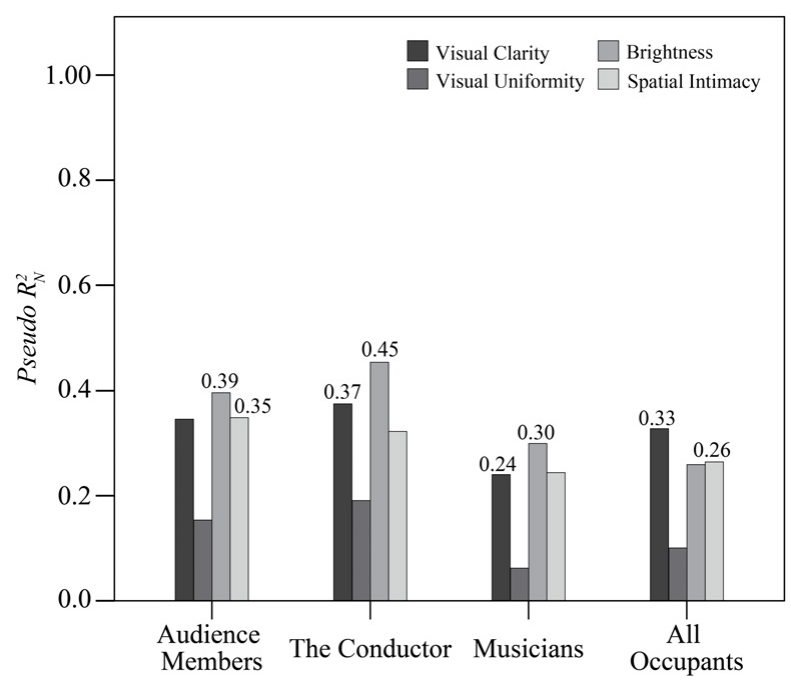

Taken together, we found satisfactory regression relationships with selected measures for perceived visual clarity (average $R_{N}^{2}=0.33$; S.D. $=0.06$ ), visual uniformity (average $R_{N}^{2}=0.10$; S.D. $=0.06$ ), brightness (average $R_{N}^{2}=0.26$; S.D. $=$ 0.09 ) and spatial intimacy (average $R_{N}^{2}=0.26$; S.D. $=0.05$ ). Worth noting is that the relationships were observed to be stronger when analysing them by role (Figure 9).

\section{Conclusions}

Through novel combinations of conventional and current research methods, including those from visual perception, acoustics and HDR image processing, we tested our methodological developments to evaluate the effects of concert luminance appearance on impressions in Cambridge King's College Chapel. Lighting perception is relative. We recognised that having as many stimulus conditions as possible would lead to a more reliable and comprehensive interpretation. The context of the chapel and its constraints influenced the development, for example, the number and configuration of the light settings tested. 
The use of a real complex setting has proved a challenge, yet the unique context and light levels studied have contributed valuable insights towards the way we attempt to understand the relationships between luminous spaces and occupants’ experiences.

This study has developed a rigorous approach to measuring light, gauging perceived quality, defining variables, identifying links between what is perceived and what is measured, and testing validity and reliability. It is important to reiterate that this study did not strive for absolute accuracy in specifying the subjective-objective relationships. Facts about human vision were related with photometric data to examine luminance distributions, edges and patterns of visual images. We observed some strong associations with the measures that relate to the structure of the visual field but disappointingly not with the visual angle subtended at the eye. The application of binary masks as tools to identify and extract key visual details enabled us to describe the visual scenes numerically, facilitating the analysis of subjective responses to lighting conditions. The masks however only accounted for the most informative regions of the scenes where the eyes were likely to fixate. Another shortcoming of this technique is that the binary nature of the masks did not reflect the variability in visual attention drawn to various parts of a scene. It was unlikely that the participants, whether they be audience members, the conductor or musicians, would fixate on a single view throughout the experiment. For future work, it is recommended to weight the binary data by means of probability, for example, in order to provide a better representation of how we see things.

Today, we still lack the ability to fully retrieve and understand the mental images the human brain relies on to make interpretations. It is now possible to make predictions about visual discomfort from images using Penacchio and Wilkins' algorithm by comparing the spatial structure of an image to natural scenes, by analysing 
its difference in colour, as well as by relating it to the sensitivity of human visual system. ${ }^{68,69}$ With the technological advances in eye tracking, pattern recognition and augmented reality, it would not be a surprise if, in the near future, a robotic eye might be developed capable of replicating human eye movements and of capturing and analysing visual images simultaneously.

Unlike previous studies, we took into consideration the differences among the viewing positions, occupants' types and occupants’ luminance requirements. Visual Clarity, Visual Uniformity, Brightness and Spatial Intimacy all were found to be moderately strongly associated with the objective measures studied. Acuity-related variables (e.g. VA Stage) appear to have the strongest association with perceived clarity. Uniformity-related measures (e.g. $\mathrm{LLM}_{\mathrm{avg}}: \mathrm{LRM}_{\mathrm{avg}}$ ) were found to be the stronger variables for perceived visual uniformity, brightness and spatial intimacy, while relative luminance-based (e.g. RLavg) and geometric-based (e.g. Area Light Patches) measures were observed to be secondary variables in most cases.

It seems that placing people in a luminous environment and asking them for feedback is perhaps the most reliable way to understand lighting quality, but even this will not satisfactorily address all aspects of lighting perception. In order to increase the reliability of responses and facilitate more meaningful comparisons between similar studies, it is recommended to check that research participants comprehend the attributes and their definitions as intended by researchers. What this study also highlights is that it is useful to consider ordered logistic regression modelling and examine the responses in relation to the occupant's role as alternative approaches to analysing the subjectiveobjective relations, as that might shore up the weak and null results.

This has been the first study to conduct extensive field experiments in a historic environment and study the resulting lighting perceptions. The most extensive research 
has been on office environments, which is unsurprising because of the practical need. But in fact the lighting community has generally refrained from conducting research in other environments owing to the complexity brought about by culture, expectations and architecture. $^{70}$ The work of Waldram, which aimed to assess the applicability of the designed appearance method, conducted in the fifties has been the only previous study sited in a historic church. ${ }^{14,71}$ Future research focusing on real settings with architectural significance could perhaps help move this research field forward.

\section{Conflict of interest}

The authors declared no potential conflicts of interest with respect to the research, authorship and/or publication of this article.

\section{Funding}

The authors disclosed receipt of the following financial support for the research, authorship, and/or publication of this article: This study was supported by the Cambridge Trust, Emmanuel College and the Cambridge Department of Architecture.

\section{Acknowledgements}

The authors would like to thank Cambridge King's College for granting private access to its chapel. The authors were grateful to all the research participants for their time and effort, and Dr Tom White for his technical assistance. 


\section{References}

1. Galasiu AD, Newsham GR, Suvagau C and Sander DM. Energy saving lighting control systems for open-plan offices: a field study. Leukos 2007; 4: 7-29.

2. Bellia L, Musto M, Spada G. Illuminance measurements through HDR imaging photometry in scholastic environment. Energy and Buildings 2011; 43: 2843-2849.

3. Moore T, Carter DJ, Slater AI. User attitudes toward occupant controlled office lighting. Lighting Research and Technology 2002; 34: 207-219.

4. Fostervold KI, Nersveen J. Proportions of direct and indirect indoor lighting: the effect on health, well-being and cognitive performance of office workers. Lighting Research and Technology 2008; 40: 175-200.

5. Denk E, Jimenez P, Schulz B. The impact of light source technology and colour temperature on the well-being, mental state and concentration of shop assistants. Lighting Research and Technology 2015; 47: 219-233.

6. Tonello G, Hernandez de Borsetti N, Borsetti H, Tereschuk L, Lopez Zigaran S. Perceived well-being and light-reactive hormones: an exploratory study. Lighting Research and Technology 2019; 51: 184-205.

7. Lewin I, Bell WB. Luminance measurement by photographic photometry. Illuminating Engineering 1968: 582-589.

8. Lewin I, O'Farrell J. Luminaire photometry using video camera techniques. Journal of the Illuminating Engineering Society 1999; 28: 57-63.

9. Bellia L, Cesarano A, Minichiello F, Sibilio S. Setting up a CCD photometer for lighting research and design. Building and Environment 2002; 37: 1099-1106.

10. Inanici MN. Evaluation of high dynamic range photography as a luminance data acquisition system. Lighting Research and Technology 2006; 38: 123-136.

11. Loe DL, Mansfield KP, Rowlands E. A step in quantifying the appearance of a lit scene. Lighting Research and Technology 2000; 32: 213-222.

12. Veitch JA, Stokkermans MGM, Newsham GR. Linking lighting appraisals to work behaviors. Environment and Behavior 2013; 45: 198-214.

13. Rea MS, Ouellette MJ. Relative visual performance: a basis for application. Lighting Research and Technology 1991; 23: 135-144.

14. Waldram JM. Studies in interior lighting. Transactions of the Illuminating Engineering Society 1954; 19: 95-133.

15. Hopkinson RG. Assessment of brightness: what we see. Journal of the Illuminating Engineering Society 1957; 52: 211-222. 
16. Padgham CA, Saunders JE. The Perception of Light and Colour. London: G. Bell and Sons, 1975: 48-50.

17. Weber EH. De Pulsu, Resorptione, Auditu et Tactu Annotationes Anatomicae et Physiologicae Leipsic. Leipzig: C.F. Koehle, 1834.

18. Thurstone LL. Attitudes can be measured. American Journal of Sociology 1928; 33: 529-554.

19. Blackwell HR. Contrast thresholds of the human eye. Journal of the Optical Society of America 1946; 36: 624-643.

20. Blackwell HR. Development and use of a quantitative method for specification of interior illumination levels. Journal of the Illuminating Engineering Society 1959; 54: 317-353.

21. Cuttle C. Lighting patterns and the flow of light. Lighting Research and Technology 1971; 3: 171-189.

22. Cuttle C. Cubic illumination. Lighting Research and Technology 1997; 29: 114.

23. Rea MS, Jeffrey IG. A new luminance and image analysis system for lighting and vision: I. Equipment and calibration. Journal of the Illuminating Engineering Society 1990; 19: 64-72.

24. Flynn JE, Spencer TJ, Martyniuk, Hendrick C. Interim study of procedures for investigating the effect of light on impression and behavior. Journal of the Illuminating Engineering Society 1973; 3: 87-94.

25. Flynn JE. A study of subjective responses to low energy and non-uniform lighting systems. Lighting Design and Application 1977; 7: 6-15.

26. Hawkes RJ, Loe DL, Rowlands E. IERI: A note towards the understanding of lighting quality. Journal of the Illuminating Engineering Society 1979; 8: 111-120.

27. Loe DL, Mansfield KP, Rowlands E. Appearance of lit environment and its relevance in lighting design: experimental study. Lighting Research and Technology 1994; 26: 119-133.

28. Osgood CE. The nature and measurement of meaning. Psychological Bulletin 1952; 49: 197-237.

29. Kruskal JB. Multidimensional scaling by optimizing goodness of fit to a nonmetric hypothesis. Psychometrika 1964; 29: 1-27.

30. Shakhnovich AR. The Brain and Regulation of Eye Movement. New York: Plenum Press, 1977: 23-24. 
31. Agresti A. Categorical Data Analysis. 2nd ed. Hoboken, NJ: WileyInterscience, 2002: pp. 115-123, 269-270, 289-290.

32. Hosmer DW, Lemeshow S, Sturdivant RX. Applied Logistic Regression. 3rd ed. Hoboken, New Jersey: John Wiley \& Sons, 2013.

33. Stone PT, Parsons KC, Harker SDP. Research note: subjective judgements of lighting in lecture rooms. Lighting Research and Technology 1975; 7: 259-261.

34. Pellegrino A. Assessment of artificial lighting parameters in a visual comfort perspective. Lighting Research and Technology 1999; 31: 107-115.

35. Newsham GR, Veitch JA. Lighting quality recommendations for VDT offices: a new method of derivation. Lighting Research and Technology 2001; 33: 97-116.

36. Houser KW, Tiller DK, Bernecker CA, Mistrick RG. The subjective response to linear fluorescent direct/indirect lighting systems. Lighting Research and Technology 2002; 34: 243-264.

37. Custers PJM, de Kort YAW, IJsselsteijn WA, de Kruiff ME. Lighting in retail environments: atmosphere perception in the real world. Lighting Research and Technology 2010; 42: 331-343.

38. Schielke T, Leudesdorff $M$. Impact of lighting design on brand image for fashion retail stores. Lighting Research and Technology 2015; 47: 672-692.

39. Inanici MN, Galvin J. Evaluation of high dynamic range photography as a luminance mapping technique. Berkeley, CA: Lawrence Berkeley National Laboratory, 2004: pp. 1-28.

40. Mardaljevic J, Painter B, Andersen M. Transmission illuminance proxy HDR imaging: a new technique to quantify luminous flux. Lighting Research and Technology 2009; 41: 27-49.

41. Fan D, Painter B, Mardaljevic J. A data collection method for long-term field studies of visual comfort in real-world daylit office environments: Proceedings of The 26th Conference on Passive and Low Energy Architecture, Quebec City, Canada, 2224 June 2009: pp. 22-24.

42. Tural M. On post occupancy evaluation of the luminous environment: an approach to integrate high dynamic range image analysis and simulation into the evaluation process: The 39th ASES National Solar Conference Proceedings, Phoenix, Arizona, 17-22 May 2010: pp. 1312-1317.

43. Debevec PE, Malik J. Recovering high dynamic range radiance maps from photograph. In: SIGGRAPH, Los Angeles, CA, 3-8 August 1997: pp. 369-378.

44. Drago F, Martens WL, Myszkowski K, Chiba N. Design of a tone mapping operator for high dynamic range images based upon psychophysical evaluation and 
preference mapping: Proceedings of SPIE - The International Society for Optical Engineering, Santa Clara, CA, 17 June 2003: pp. 321-331.

45. Ward G. The RADIANCE lighting simulation and rendering system: SIGGRAPH, Orlando, CA, 24-29 July 1994. pp. 459-472.

46. Ward G. Rendering with Radiance: The Art and Science of Lighting Visualization. San Francisco: Morgan Kaufmann, 1998.

47. Moeck M, Anaokar S. Validation of high dynamic range imaging to luminance measurement. Leukos 2005; 2: 133-144.

48. Inanici MN, Navvab M. The virtual lighting laboratory: per-pixel luminance data analysis. Leukos 2006; 3: 89-104.

49. Painter B, Mardaljevic J, Fan D. Monitoring daylight provision and glare perception in office environments: Proceedings of W098 \& W111-Special Track 18th CIB World Building Congress, Salford, UK, 10-13 May. 2010: pp. 148-160.

50. Konis K, Lee ES, Clear RD. Visual comfort analysis of innovative interior and exterior shading systems for commercial buildings using high resolution luminance images. Leukos 2011; 7: 167-188.

51. Cai H. Luminance gradient for evaluating lighting. Lighting Research and Technology 2016; 48: 155-175.

52. van den Wymelenberg K, Inanici MN. A critical investigation of common lighting design metrics for predicting human visual comfort in offices with daylight. Leukos 2014; 10: 145-164.

53. Zhao N, Reinhart CF, Paradiso JA. Image-based perceptual analysis of lit environments. Lighting Research and Technology. First published 19 July 2018. DOI: 1477153518786768.

54. Lo VWL, Steemers KA. Measuring light in field experiments using dummies and objects: A study of concert lighting. Lighting Research and Technology 2018; 6: 827-841.

55. Beranek L. Music, Acoustics and Architecture. New York: John Wiley and Sons, 1962.

56. Barron M. Subjective study of British symphony concert halls. Acustica 1988; 66: 1-14.

57. Flynn JE. Lighting-design decisions as interventions in human visual space. In: Nasar JL, (ed.). Environmental Aesthetics: Theory, Research, and Applications. Cambridge: Cambridge University Press, 1988: 156-170. 
58. Flynn JE, Hendrick C, Spencer $\mathrm{T}$ and Martyniuk O. IERI: a guide to methodology procedures for measuring subjective impressions in lighting. Journal of the Illuminating Engineering Society 1979; 8: 95-110.

59. Flynn JE, Kremers JA, Segil AW and Steffy GR. Architectural Interior Systems: Lighting, Acoustics, Air Conditioning. 3rd ed. New York: Van Nostrand Reinhold, 1992: 11-20.

60. Reid F. Techniques of stage lighting. Lighting Research and Technology 1970; 2: $125-135$.

61. Reid F. The Stage Lighting Handbook. 6th ed. London: A\&C Black, 2001.

62. Lo VWL, Steemers K. An occupant's role-specific approach to identifying lighting parameters for concert performances in Cambridge King's College Chapel: Proceedings of The 33rd PLEA International Conference: Design to Thrive, Edinburgh, UK, 2-5 July 2017: pp. 3261-3268.

63. MathWorks. MATLAB: The Language of Technical Computing. Getting Started with MATLAB. Version 7. Natick, Massachusetts: MathWorks, 2005.

64. Ruch TC, Fulton JF. Medical Physiology and Biophysics. 18th ed. Philadelphia: W.B. Saunders, 1960: 453.

65. Hogan MJ, Alvarado AB and Weddell JE. Histology of the Human Eye: An Atlas and Textbook. Philadelphia: W.B. Saunders, 1971: pp. 491-498.

66. Spector WS. Handbook of Biological Data - The Visual Mechanism: Morphology and Physiology. Philadelphia: W.B. Saunders, 1956: pp. 316-317.

67. Fotios S, Atli D. Comparing judgments of visual clarity and spatial brightness through an analysis of studies using the category rating procedure. Leukos 2012; 8: 261281.

68. Penacchio O, Wilkins AJ. Visual discomfort and the spatial distribution of Fourier energy. Vision Research 2015; 108: 1-7.

69. Le ATD, Payne J, Clarke C, Kelly MA, Prudenziati F, Armsby E, Penacchio O and Wilkins AJ. Discomfort from urban scenes: Metabolic consequences. Landscape and Urban Planning 2017; 160: 61-68.

70. Society of Light and Lighting. The SLL Code for Lighting. London: CIBSE, 2012: pp. 17-18.

71. Waldram JM. The lighting of Gloucester Cathedral by the 'designed appearance' method. Transactions of the Illuminating Engineering Society 1959; 24: 85-105. 